\title{
Modelling Inflation Uncertainty with Structural Breaks Case of Turkey (1994-2013)
}

\author{
Pınar Göktaş and Cem Dişbudak \\ Department of Economy, Faculty of Economy and Administration, Muğla Sitkı Koçman University, 48000 Muğla, Turkey \\ Correspondence should be addressed to Pınar Göktaş; pinargoktas@mu.edu.tr
}

Received 26 July 2014; Accepted 24 August 2014; Published 11 September 2014

Academic Editor: Erol Egrioglu

Copyright (C) 2014 P. Göktaş and C. Dişbudak. This is an open access article distributed under the Creative Commons Attribution License, which permits unrestricted use, distribution, and reproduction in any medium, provided the original work is properly cited.

In recent years, the importance attached to the concept of volatility has increased and become a phenomenon frequently encountered in every field ranging from financial markets to macroeconomic indicators. In this study, inflation data obtained from CPI index for the period of 1994:01-2013:12 in Turkey was used to determine the best representative of the inflation uncertainty. To realize this, both symmetric and asymmetric GARCH-type models were employed. Since there are many factors that may lead to structural change within the economic course of Turkey, a structural break in the series has first been investigated. By administering Bai-Perron structural break test, two different break points both in mean and variance have been detected to be in February 2002 and in June 2001, respectively. The inclusion of those break points to the related equations, appropriate forecasting models were projected. Moreover it was found that, while in the periods prior to the break in both variance and mean the inflation itself was the reason for inflation uncertainty, following the dates of the break, the relationship changed bidirectionally. In the meantime, when the series was taken as a whole without considering the break, bidirectional causality relationship was also detected in the series.

\section{Introduction}

From statistical point of view, "volatility" is mostly considered to be variance of a series and dealt with as the measurement of a deviation of a random variable from its mean. Inflation volatility is on the other hand related to fluctuations (or instability) in a selected inflation series [1]. Hence, inflation volatility is not only the measurement of the severity of the unexpected changes in inflation but also explains unforeseen components of inflation stemming from recurring external shocks in the series [2].

Uncertainty results from the difficulty of estimating the future values of the investigated variable. More clearly, uncertainty means impossibility of determining the likelihood of the future events [3]. In this connection, inflation uncertainty can be roughly defined as unpredictability of the future price level. Here, unpredictability means uncertainty in forecasting [4]. Hence, high uncertainty reflects higher volatility of the expected value of the variable or higher volatility around a certain mean.
It may be useful to know that changes occurring in inflation may stem from inflation's own dynamics and though there is no possibility to affect the volatility, it is possible to decrease the uncertainty. Moreover, even when the expected and desired stable inflation is achieved and sustained, problems may also emerge due to many different political factors and elements. Thus, it would not be wrong to conclude that variability of inflation is indispensable. In this regard, making use of inflation uncertainty measurements is of great importance to produce preventive policies.

There are many methods developed from the early periods when values such as standard deviation or variance were used to determine not directly observable inflation uncertainty up to present time in which GARCH-type volatility prediction models are widely used to predict the volatility. Moreover, in the traditional time series models used before volatility forecasting methods, it was assumed that the variance is stable within time. However, many of the economic series exhibit a structure with changing variance 
and GARCH methods provide an opportunity to model this and this is a big advantage of them.

The main purpose of the present study is to determine the forecasting model that can best represent the inflation uncertainty in the researched period (1994:01-2013:12). There is a great deal of research and many resources and empirical applications in this field in the world and in Turkey. Yet, different from the existing research including structural changes taking place in inflation as an external variable in the model, in the current study, the models constructed at volatility forecasting stages were predicted using the dates of breaks.

Not conducting any transition for stabilization in the series, the operation of removing the seasonal influences through dummy variables allows modeling without making any changes based on any adjustments on the series. In this context, though there are many methods and tests to determine the structural breaks in series proposed in the literature, one of the most commonly used methods, BaiPerron (BP) structural break test, was used in the present study to elicit more than one structural break. By including February 2002 break and June 2001 break determined through the above mentioned method into mean equation and variance equation, it was found that the forecasting model best representing inflation uncertainty is EGARCH $(1,1)$.

At the same time, the study investigated whether the emerging of the change occurring in the volatility structure before the change occurring inflation mean structure results in any change in the direction of the relationship between inflation and its uncertainty. While in the periods prior to the break in both variance and mean, inflation was the reason for inflation uncertainty, following the dates of the break, the relationship changed bidirectionally. Thus, the change at structural level taking place in the direction of the decrease seen in the uncertainty in 2001 led to the change at structural level in the mean of inflation, and since then, they have been in mutual interaction.

\section{Literature Review}

In recent years, the importance attached to the concept of volatility has increased and it has become a phenomenon frequently encountered in every field ranging from financial markets to macroeconomic indicators. Moreover, economic, political, and similar expectations of actors in real and financial markets may cause volatility at varying extents. However, each market gives responses to these factors at different scales and particularly negative expectations and unexpected developments such as crises may yield negative results affecting the whole economy due to high volatility they create. While every type of uncertainty may lead to negative outcomes in economy, destruction caused by inflation can be quite costly.

As a result, inflation and all the related concepts have always been the focus of research for investigators of all kinds. In macroeconomy, inflation research focuses on three basic features of the dynamics of inflation being mean inflation or level of inflation, permanence of inflation, and variability of inflation. In addition, while there is a great amount of research on the first two features of inflation, there is a limited amount of research on variability of inflation, particularly in developing countries [2]. And research on variability of inflation in the literature focuses on two basic arguments. The first argument is about the revelation of the structure of the relationship between inflation and its uncertainty and the second one is about the determination of the best proxy of inflation uncertainty.

Particularly because of the adverse impacts on economic growth and income distribution, there is a general consensus that inflation uncertainty yields uncertainty in various economic and financial variables. Yet, there are many different evaluations of arguments presented in the literature, possible correlation between inflation and its uncertainty has a long and well-known history. The importance of eliciting the scope of this correlation and predicting the direction of causal relationships was first emphasized in the work of Okun in 1971 [5]. In a similar manner, Friedman in [6] proved that higher mean inflation leads to inflation uncertainty causing more costs.

Following this study, the investigation of the relationship between inflation rate and its uncertainty gained momentum and occupied an important place in theoretical and empirical macroeconomic research. Such that, Okun and Friedman's argument that high inflation leads to higher inflation was accepted by many economists as a valid phenomenon. This argument intuitively proposed by Friedman was taken one step further by Ball, 1992, in [7] arguing that higher inflation results in increasing uncertainty on monetary policy. This preliminary research laid the basis for other theories investigating and determining the relationships at different directions. It can be argued that theoretical literature dealing with causality relationship between inflation and its uncertainty is built on two basic assumptions one of which is the hypothesis of Friedman-Ball proposing that inflation increases the uncertainty of inflation and the other is the hypothesis of Cukierman-Meltzer proposing that inflation uncertainty increases inflation. Of course, a great deal of research has been conducted to test all these hypotheses both in the world and in Turkey.

As a result, no agreement has been reached among empirical studies as the validity of these hypotheses still maintaining their theoretical importance is sensitive to the related economy, period, data set, and followed econometric method [8].

The research aiming to determine the best representative of inflation uncertainty that is the second important stage of the discussions in the literature focuses on the measurement of uncertainty. This research is of great importance in terms of predicting long-term uncertainty of inflation in underdeveloped and developing countries showing weaknesses in macroeconomic indicators and financial markets and suffering from price stability. Inflation uncertainty is not a directly observable variable, which has brought about many econometric method applications to attain uncertainty.

In the early periods of volatility research, inflation uncertainty was represented by moving standard deviation and 
variance of inflation series and in this line of research, rather than the uncertainty of inflation, its variability was explored. However, these approaches represented by variance could not distinguish predictable and unpredictable changes in inflation and this created an important problem. Furthermore, as the uncertainty of inflation changes over time, traditional time series models built on constant variance assumption are inadequate [9].

As can be seen while volatility was measured through the variance value assumed to be constant, particularly in recent years, it has been stated in research dealing with high frequency series such as exchange rate, interest rate, and inflation, that the variance is not constant. In order to eliminate this shortcoming in the research, inflation models allowing the change of variance over time have been developed. In this connection, the direction and size of the change taking place in the volatility are represented by three unconditional variances in the literature. First one is the standard deviation (historical volatility); the second one is heteroskedasticity and autocorrelation (HAC) predictor of the variance. Finally, square root of unconditional variance of the most appropriate GARCH-type models is used and proposed unconditional variance is calculated. This makes the investigation of the change of volatility throughout the related period possible [10].

In short, since the early periods when volatility was considered to be the standard deviation of the related variable, numerous methods have been developed over time. However, for the first time, Engle in [11] proposed to model the relationship between inflation rate and inflation variance through autoregressive conditional changing variance $(\mathrm{ARCH})$ method introduced to the literature by himself and used conditional variance as the representative of inflation uncertainty. When the literature is reviewed, it is seen that though proposed to model inflation data, ARCH model has become a powerful method for the analysis of economies and financial markets of all the other developed countries. Following the development of this model, many researchers have employed GARCH-type models to test inflation uncertainty.

Furthermore, GARCH-type models have been demonstrated as superior to the earlier method of using the unconditional variance of inflation as a proxy for uncertainty [12]. As these models are particularly useful when volatility changing over time is desired to be modeled, they have become the basis of dynamic modeling. Moreover, in addition to their practicality in forecasting, they allow the application of diagnostic tests [13].

Therefore, inflation uncertainty is generally expressed as conditional volatility obtained from GARCH models [14] and $\mathrm{ARCH}$ models are preferred in the literature to standard changing variance methods calculated as the moving average of error squares [15]. Moreover, when the other studies deal with the situation in Turkey, it is seen that mostly ARCH and GARCH methods are used to obtain inflation uncertainty [8].

In this regard, there are many empirical studies both in the world and in Turkey analyzing the related discussions separately or together such as [16-31] from other countries and [32-39] from Turkey.
Univariate GARCH models consist of two equations. First one is mean equation describing the data observed as a function of the other variables and error term. The second one is the variance equation showing the change of conditional variance as a function of past conditional variance and lagged error terms [40]. In this context, in the present study, volatility forecasting model best representing inflation uncertainty will be determined by constructing mean and variance equations to model inflation volatility.

In model estimation, whether the time series included in regression reflect the actual relationship and validity and reliability of predictions is closely related to the stability of the series. As it is not possible to use nonstationary series in regression, they should be stabilized using suitable transformation. In order to determine whether series are stationary or not, augmented Dickey-Fuller (ADF) test, Philips-Perron (PP), and Kwiatkowski-Phillips-Schmidt-Shin (KPSS) unit root tests are the most widely used methods in the literature; yet, they are criticized as they do not make use of structural break.

Though there is a general agreement that in traditional unit root hypotheses, the shocks are temporary and do not change the route of the series in the long run, Nelson and Plosser [41] argue that almost all macroeconomic time series have unit root. Findings indicating that random shocks have permanent impacts on macrolevel, that is, fluctuations are not temporary, have revived the interest in unit root and fuelled the discussions. Unit root literature focuses on whether the series is affected by temporary or permanent shocks [42]. In order to test these impacts, Dickey-Fuller in [43], PhillipsPerron in [44] and KPSS in [45] developed models most widely used in applications; yet, they have been criticized as they do not take structural break into consideration. That is, the possibility of confusing the state of being not stable with an existing break in the series is a serious weakness of traditional unit root tests [46-48].

Revelation of this weakness in applications led to the development of tests considering potential structural breaks in series [49-51]. Thus, depending on the number of breaks and whether the break is internal or external, numerous methods have been developed based on convergence techniques and they have been used very much in empirical applications. Though there are many methods and tests to determine the structural break in series in the literature, in the present study, Bai-Perron (BP) structural break test, one of the methods most frequently used in the detection of more than one structural break, was employed.

\section{Methodology}

3.1. Volatility Forecasting Models. The aim of volatility forecasting models is to explain the course of volatility, estimate their parameters, and use this information for the prediction of volatility in the future. In the proposed methods to analyze the uncertainty in economy, first aim is to model volatility that is the measurement of the extent to which the concerned variable deviate from their expected value. Though applications in great majority of the known econometric methods 
in time series refute this to a great extent, variance taken as the measurement of uncertainty is assumed to be constant in time. The weak stationarity assumption on which linear modeling methods are based is violated in many economic time series such as interest rates, exchange rates, and CPI.

There are many methods discussed in the literature to measure volatility and among these, historical mean, moving average, random walk, exponential smoothing, exponential weighted mean, simple regression, and ARCH-GARCH processes are the prominent ones [52]. However, in early studies of uncertainty conducted with these forecasting models, variability was used in place of uncertainty. After Engle [11] developed the ARCH model, attention was directed to the conditional variance. Over time, the difference between variability and uncertainty was recognized and instead of variability expressed with unconditional variance as a measurement of uncertainty, volatility expressed with conditional variance started to be used. Moreover, constant variance assumption could not be realized in most of time.

The second method introduced after ARCH model was the generalized ARCH model (GARCH) developed by Bollerslev in [53]. This model was widely preferred in research conducted using financial and economic time series due to its similarity to ARMA and easiness in calculation and interpretation [54] as

$$
h_{t}=\omega+\sum_{i=1}^{q} \alpha_{i} \varepsilon_{t-i}^{2}+\sum_{j=1}^{p} \beta_{j} h_{t-j} .
$$

In $\operatorname{GRACH}(q, p)$ model shown above, in order to meet the condition that conditional volatility should be positive, $\omega>0, \alpha_{i} \geq 0$ and $\beta_{j} \geq 0$ should not be nonnegative. The constraint $\sum \alpha_{i}+\sum \beta_{j}<1$ called variance should be finite and constant in time. Here, $h_{t}$ stands for conditional variance, $\varepsilon_{t}$ represents the smallest squares residuals in time $t,(q)$ shows the level of the ARCH term, and $(p)$ shows that level of the GARCH term. The equality turns into $\operatorname{ARCH}(q)$ process when $p=0$ and when $p=q=0$, error terms turn into white noise process [53]. Moreover, as GARCH model includes only three parameters being term weighted mean of $\omega, \varepsilon_{t-i}^{2}$ mean equation error squares volatility information $i$ period ago and predicted variance $h_{t-j} j$ period ago, it is a more economic method than ARCH [55].

As can be seen, GARCH variance estimation is the weighted mean of three different variance estimations. The first one is the constant variance corresponding to long-term mean, and the second one is the estimation made in the prior period and the last one is new information that did not exist when the estimation was made in the prior period. This information can be viewed as estimation variance based on one-period information. At the same time, weights belonging to these three estimations predict how fast variance change in the face of new information and turn into long-term mean [56].

The parameters $\alpha$ and $\beta$ in GARCH model account for short-term volatility dynamics in series. The $\alpha$ represents the short-term permanence of the shocks whereas $\beta$ represents their long-term permanence. In the model, the size of $\alpha$ coefficient corresponding to the term of $\mathrm{ARCH}$ means intense reactions to the changes taking place in economy and size of $\beta$ coefficient means that disappearance of shocks occurring within $t$ time in conditional variance; thus, it results in permanent change in the future value of conditional variance; that is, volatility is permanent [57].

GARCH specification has become an important tool in modeling time-dependent volatility since the works of [11, 53]. It was shown that ARCH models provide surprisingly good estimations for conditional volatilities [58]. Moreover, Engle [56] stated that interpretation of the model is easy to understand and in many cases, GARCH is a good starting point though it is always possible to find a little better model among many forecasting models proposed in the literature. Thus, though frequently used in empirical studies due to the properties it possesses, the assumption that GARCH model conditional variance gives symmetric respond against positive or negative shocks is usually not supported particularly in financial series [56].

The sign of asymmetry indicates a tendency in which negative shocks produce greater reaction than positive shocks. While focusing on the size of volatility, overlooking its sign sometimes results in GARCH model's inadequacy in the modeling of conditional variance. In order to model asymmetric impacts on volatility in time series and guarantee that conditional volatility in GARCH model should be nonnegative, Nelson [59] proposed the Exponential GARCH called EGARCH model. This model in fact is a kind of adaptation of GARCH model as follows:

$$
\begin{aligned}
\log h_{t}= & w+\sum_{j=1}^{q} \beta_{j} \log h_{t-j}+\sum_{i=1}^{p} \alpha_{i}\left|\frac{\varepsilon_{t-i}}{\sqrt{h_{t-i}}}\right| \\
& +\sum_{k=1}^{r} \gamma_{k} \frac{\varepsilon_{t-k}}{\sqrt{h_{t-k}}},
\end{aligned}
$$

where $\left(h_{t}\right)$ is the logarithm of the conditional variance and no matter what the coefficients are, positivity of $\left(h_{t}\right)$ is always guaranteed [60]. In the meantime, the response given by the conditional volatility to shocks can be measured with the $\gamma_{k}$ parameter; in case of $\gamma_{k}=0$ the response becomes symmetric. In financial time series, fitting the EGARCH model to obtain conditional volatility on past negative shocks will result mostly in $\left(\alpha_{i}-\gamma_{i}\right)$ impact amount and past positive shocks will result mostly in $\left(\alpha_{i}+\gamma_{i}\right)$ impact amount. As a matter of fact, in most cases, when a negative shock occurs, the $\left(\alpha_{i}-\gamma_{i}\right)$ term becomes greater than the $\left(\alpha_{i}+\gamma_{i}\right)$ term for the desired negative of $\gamma_{i}$ (leverage effect).

The properties of EGARCH model made it preferable particularly among asymmetric forecasting models and Alexander [61] proved that, when compared to other asymmetric conditional variances, it is superior.

Another GARCH method having the capacity of modeling leverage effects is GJR-GARCH also called the Threshold GARCH (TGARCH), which was developed by Glosten et al. [62] and Zakoian [63] independently of each other. If both of 
the works are summarized in a single framework, TGARCH or GJR-GARCH model could be presented as follows:

$$
\begin{aligned}
& \sigma_{t}^{2}= \omega+\sum_{i=1}^{p} \alpha_{i} \varepsilon_{t-i}^{2}+\sum_{i=1}^{p} \gamma_{i} S_{t-i} \varepsilon_{t-i}^{2} \\
&+\sum_{j=1}^{q} \beta_{i} \sigma_{t-j}^{2}, \\
& S_{t-i}=\left\{\begin{array}{ll}
1 & \varepsilon_{t-i}<0 \\
0 & \varepsilon_{t-i} \geq 0
\end{array}\right\},
\end{aligned}
$$

where $\omega, \alpha_{i}, \beta_{i}$, and $\gamma$ are constant of the model parameters; if $\varepsilon_{t-i}$ is less than zero, then $s_{t-i}$ will be " 1 " and otherwise it will be "0".

Depending on whether the threshold value $\varepsilon_{t-i}$ is under or over $0, \varepsilon_{t-i}^{2}$ has different effects on conditional variance $\sigma_{t}^{2}$. When $\varepsilon_{t-i}$ is positive, the total effect is given by $\alpha_{i} \varepsilon_{t-i}^{2}$ and when it is negative, it is given by $\left(\alpha_{i}+\gamma_{i}\right) \varepsilon_{t-i}^{2}$. This is why, to have greater effects for bad news, $\gamma_{i}$ should be positive [60].

\subsection{Investigating Structural Break with Bai-Perron Method} and Volatility Forecasting Models. Macroeconomic time series may undergo changes under the influence of economic crises, economic regime and political changes, technological developments and innovations, natural disasters, wars, depressions, and so forth. Lack of attention paid to these changes in research may bring about many negative outcomes ranging from making mistakes at the very beginning of forecasting process to determination of incorrect model. Therefore, it is necessary to determine whether the variable under consideration has been subjected to any structural break. One of these determination methods is Bai-Perron (BP) structural break test allowing internal and multiple breaks and widely used in research. This test was introduced to the literature by Bai [64] and Bai and Perron [65-68].

The most important feature of BP procedure is that it lets forecasting both the number and location of breaks with their autoregressive coefficients [69]. In addition to this, there is another important feature of the method. One of the most important advantages of the method is allowing heteroskedasticity and autocorrelation in error. In order to be able to deal with nonparametric autocorrelation problem, it is suggested that errors should be corrected by either using Newey-West procedure or including their lags in the model [70]. Meanwhile, it makes both the independent and error term have different distributions across subperiods.

Multiple-regression model used in Bai-Perron multiple structural break test and constructed by considering $m$ break $(m+1$ regime $)$ is presented as follows:

$$
Y_{t}=x_{t}^{\prime} \beta+z_{t}^{\prime} \delta_{j}+u_{t}
$$

For $j=1, \ldots, m+1, t=T_{j-1+1}, \ldots, T_{j}$ and $T_{0}=$ 0 and $T_{m+1}=T$, period, $y_{t}$ dependent variable, $\beta$ and $\delta_{j}(j=1, \ldots, m+1)$ corresponding coefficient vectors and $\left(T_{1}, \ldots, T_{m}\right)$ indexes show unknown break points. The main purpose is to forecast break points together with regression coefficients $[65,66]$. From (4) it is seen that independent vector of variables $x_{t}^{\prime}(\mathrm{px} 1)$ and $z_{t}^{\prime}(\mathrm{qx} 1)$ on the right hand side of the model are divided into two groups representing unchanged parameters across each subperiod and have coefficients that are regime specific respectively.

The first break occurs in $T_{1}$ in such a way that the duration of the first period is starting from $T=1$ and ending in $T=T_{1}$ and in $T=T_{2}$ in such a way that the duration of the second period is from $T_{1}+1$ to $T_{2}$. As $T=T_{m}$ is the last break in the process continuing in a similar manner up to $m$ th break, the duration starts from $T_{m}+1$ and goes on until the end of the data [69].

While, until the introduction of Bai-Perron test, the existing tests were using standard SupWald statistics to determine the existence of a break only against null break, with Bai and Perron test, it became possible to test the alternative hypothesis expressing relatively fewer structural breaks against large number of breaks.

Though the same results are theoretically produced by Bai-Perron method and Sup-Wald test when the number of structural breaks is limited to one, Bai-Perron is more suitable for more than one structural break as it can forecast the breaks simultaneously and reforecast break points [71].

Bai and Perron [66] proposed three different alternative tests for multiple breaks in their methodology; supF-type test of fixed number of breaks $(m=k)$ versus no break $(m=0)$, binary maximum test dealing with unknown number of breaks versus null hypothesis, and $\sup F_{T}(l+1 \mid l)$ sequentially testing $l$ break null hypothesis versus $l+1$ single change.

The last of the proposed methods starts with a single break in the form of null hypothesis $l=1$ versus alternative hypothesis $l+1=2$ break and goes on until the null hypothesis is rejected. More clearly, the operation whose critical values were given again by Bai and Perron [67] first starts with $l$ number of breaks and until the subsequent test statistics $F(l+1 \mid l)$ become insignificant, break points are continued to be forecasted.

This procedure is quite useful to determine whether additional structural changes lead to significant reduction in the sum of forecasting residuals squares. In addition to this, it is emphasized that due to sequential method's advantage of considering heterogeneity in errors or subperiods, it gives better results than information criteria [72].

3.3. Volatility Forecasting Models with Structural Break. The issue of forecasting, testing, and calculation of a model including structural change has occupied an important place in both statistics and econometrics literature for more than a half century.

At that point, with the adaptation of breaks detected in mean and if there is, in variance, into mean and variance equations, transition to GARCH forecasting models will be realized. Suppose that simple $\mathrm{AR}(1)$ mean equation and 
TABLE 1: Descriptive statistics of general index inflation series (1994:01-2013:12).

\begin{tabular}{lccc}
\hline Mean & 0.023991 & Kurtosis & 13.80699 \\
Median & 0.017121 & Jarque-Bera & $1346.908(0.0000)$ \\
Maximum & 0.210129 & LB Q(6) & $483.38(0.0000)$ \\
Minimum & -0.014411 & LB Q(12) & $898.78(0.0000)$ \\
$\begin{array}{l}\text { Standard } \\
\text { deviation }\end{array}$ & 0.025391 & LB Q(24) & $1628(0.0000)$ \\
Variance & 0.00065 & LB Q(36) & $2134.3(0.0000)$ \\
Skewness & 2.148445 & $\begin{array}{c}\text { Number of } \\
\text { Observations }\end{array}$ & 239 \\
\hline
\end{tabular}

${ }^{*}$ Values between brackets are $P$ values indicating significance level.

$\operatorname{GARCH}(1,1)$ model to explain the given relationship is defined as follows:

$$
\begin{gathered}
y_{t}=\mu+\emptyset y_{t-1}+u_{t}, \\
u_{t}=\varepsilon_{t} h_{t}, \\
h_{t}^{2}=\omega+\alpha_{1} u_{t-1}^{2}+\beta h_{t-1}^{2} .
\end{gathered}
$$

First, in the model defined as $\operatorname{AR}(1)$, whether there is a break in parameters $\mu$ and $\emptyset$ parameters should be investigated. When the number of breaks $(n)$ and the location of break point $\left(k_{\text {mean, } i} i=1, \ldots, n\right)$ are estimated, it is assumed that constant and slope parameters in the model are affected. Therefore, with the addition of the break determined by administering Bai-Perron to mean equation in (5), the model has been converted to a mean model with structural breaks as in the following equation:

$$
y_{t}=\mu+\sum_{i=1}^{n} \mu_{i} D_{i}+\sum_{i=1}^{n+1} \emptyset_{i} D_{i} y_{t-1}+u_{t}
$$

When the number of breaks is " $n$ ", the dummy variable equals "1" $\left(D_{i}=1\right)$ for the break occurring in mean between $i$ th break and $(i-1)$ th break. The series becomes $D_{i}=0$, out of the location space indicated in the series. Lower bound of the period up to the first break occurring in the series represents the first observation to be $k_{\text {mean }, 0}=1$. When constructing the model, one of the dummy variables should be excluded to prevent multicollinearity. Whereas the parameter $\emptyset_{i}$ in (8) represents the slope of each period between sequential two breaks, $\mu_{i}$ gives the deviation from the mean between $i$ th subperiod and $(n+1)$ th period $[72,73]$. Basically, as the method allows changes including autoregressive coefficients, a separate $\operatorname{AR}(p)$ model forecasting is needed for each subperiod.

It is also necessary to determine whether there is a break in the variance. While whether there is such a break in the mean of the variance is investigated, simple regression of GARCH process is forecasted with the constant. By using the square of the residuals obtained from the mean equation given below $\left(u_{t}^{2}\right)$, Bai-Perron algorithm has been reperformed to following model:

$$
u_{t}^{2}=v+\sum_{i=1}^{m} v_{i} D_{i}
$$

In a similar manner, $D_{i}$ being the dummy variable takes the value of $D_{i}=1$ for $k_{\text {vari-1 }} \leq t<k_{\text {vari }}$ and when the null hypothesis of $v_{i}=0$ (no break) is rejected, there will be $m$ number of breaks. After the determination of the number of breaks of the mean of variance $(m)$ and its location $\left(k_{\text {var }}\right)$, GARCH-type model is obtained with mean equation as follows [72]:

$$
\begin{gathered}
y_{t}=\mu+\sum_{i=1}^{n} \mu_{i} D_{i}+\sum_{i=1}^{n+1} \emptyset_{i} D_{i} y_{t-1}+u_{t}, \\
u_{t}=\varepsilon_{t} h_{t}, \\
h_{t}^{2}=\alpha_{0}+\sum_{j=1}^{m} \alpha_{0, j} D_{j}+\alpha_{1} u_{t-1}^{2}+\beta h_{t-1}^{2} .
\end{gathered}
$$

When a break is detected in variance, in a similar manner, the break is included in the variance equation and GARCH model with structural break can be constructed.

\section{Empirical Analysis}

4.1. Data and Descriptive Statistics. The first question coming to mind in inflation modeling is that which inflation measurement should be used. In general, for the inflation described as the steady increase in living costs, CPI is regarded as the indicator of inflation though it is stated to be deficient measurement of general price level due to reasons such as changes in household expenditure patterns, market structure, and technology-based biases in the measurement of consumer prices [74]. More clearly, in addition to being the first indicator of living costs, it provides some advantages such as making comparisons in the international literature using primarily CPI as a dependent variable [75]. Moreover, as it interests consumers representing the majority of economic units, Mankiw [76] pointed out that CPI is used to measure inflation in majority of studies.

Furthermore, by considering the reasons such as the use of CPI in most of the inflation targeting regimes, in the present study, with the base year of 1994 monthly Consumer Prize Index data set covering 1994:01-2013:12 period was used. The data belonging to inflation series obtained through the conversion of monthly index data according to Fregert [77] were calculated with the equation as follows:

$$
\pi_{t}(\text { Inflation })=\frac{\mathrm{CPI}_{t}-\mathrm{CPI}_{t-1}}{\mathrm{CPI}_{t-1}} \approx \ln \mathrm{CPI}_{t}-\ln \mathrm{CPI}_{t-1} .
$$

The descriptive statistics belonging to general inflation series are presented in Table 1 and they are evaluated from statistical and economic point of view.

When the descriptive statistics of the inflation belonging to the general index are analyzed, it is seen that the monthly 
mean inflation is $2.39 \%$ and standard deviation is $2.54 \%$ in the period under consideration (1994:01-2013:12). The standard deviation shows the distribution of the series according to the mean and from the highness of this value, it is possible to argue that the general inflation series displays a structure scattered quite far away from the mean value. Skewness value suggests that the distribution has an appearance asymmetric towards right with its end values. Moreover, as can be seen in the histogram in Figure 1, general index inflation center has a high peak value and due to relatively greater number of observations in its tails, it has a leptokurtic appearance indicating that the tails are thick. Quite high kurtosis value indicates a distribution that is not normal. Based on JarqueBera statistics, it can be argued that depending on the pointedness of the inflation series, it is significantly far away from normality and visual findings related to the distribution are supported with the statistics given in Table 1.

When all these results are evaluated from economic viewpoint, the positiveness of the mean of the series indicates that there was a general tendency of increase in the period under investigation. Furthermore, that the series has a standard deviation higher than its mean value indicates the possibility of volatility. This indicates that many values higher than monthly average price change were observed in the economy and hence, makes us consider that the series was under the effect of volatility. Meanwhile, volatility can be clearly observed from the inflation series graph in Figure 1. The size of the difference between the maximum (1994:04) and the minimum (2011:06) values supports the idea that price changes have a high volatility.

The leptokurtic appearance of inflation series indicates that there are a large number of extreme values and rightward skewness of the series shows that unusual large shocks occurring in the series are more pervasive than small shocks and positive price changes are more likely than negative price changes. Moreover, if a distribution is skewed towards right, its mean value is higher than its median. Therefore, it can be claimed that while the intensity of the prices occurring under the mean is more than that of the prices occurring over them, the observed volatility in the price changes over the mean is larger than the volatility in the price changes occurring under the mean.

4.2. Investigation of Stationarity. In order to reveal the stationarity structure of the series belonging to CPI, its level, logarithm and monthly inflation graph has been presented in Figure 1.

When the performance exhibited by CPI series over time is examined, it is clearly seen in Figure 1(a) that there is the impact of an increasing trend in the series. In the meantime, as it is seen in Figure 1(b), taking the logarithm of CPI indicates that there is a sharp increase between 1994 and 2001. Soon after, approximately from 2002 the increment has continued but the speed of increment is not high in comparison with previous period. When it comes to the inflation series, again the volatility seen until 2002 lost its momentum as of that year and this can be seen in Figure 1(c). Though except for the quite big fluctuation observed in
1994, there was not a big fluctuation in the period under consideration, it can be argued that the series exhibited volatility to some extent. When the inflation series presented as logarithmic difference is examined in Figure 1(c), it is seen that it exhibits a descending trend, and this indicates that the series may not be stationary.

As known, in order to fulfill the assumptions of the models to be constructed in studies, the series needs to be stationary. By considering the results showing that the series may not be stationary and thus, indicating the existence of unit root, ADF, PP, and KPSS unit root tests were used to investigate the integration level of the variables and, accordingly, stationarity and the results are presented in Table 2.

When the results presented in Table 2 are examined, it is seen that only the existence of unit root cannot be rejected in the model with a constant term means of ADF unit root test the other models of ADF did not reject the null hypothesis whereas PP unit root test did not rejected null at every condition. Hence the series is stationary using both unit root tests except the model with ADF including only a constant term. In KPSS test on the contrary, the null hypothesis was rejected for both models, so that it was concluded that inflation series is not stationary. It has already been stated that rejection of the null hypotheses for both of PP and KPSS tests entails other parameters to decide whether the series are stationary or not. Though widely used in the literature, these tests are also criticized due to their bias towards not rejecting the null hypothesis in the presence of a structural break with having low power in almost integrated series [24].

Moreover, ignoring the structural break in the presence of a break results in misspecification of the model erroneous inferences about the stationarity of the series; significant level of bias towards known volatility forecasting such as moving averages in volatility forecasts increases the integration level of parameters in complex forecasting models such as GARCH and ARFIMA and the forecast persistence [72].

When all the above-mentioned reasons are considered, it seems that contradictory results obtained from unit root tests indicate the possibility of a structural break in the series; hence, first thing to be done in the period under consideration should be to investigate whether any structural change occurred in inflation. If no structural break is detected, traditional unit root test results will be capitalized on.

In the current study, in order to test whether structural break(s) occurred in the general inflation series, BaiPerron $(1998 ; 2003)[65,66]$ structural unit root test, allowing internal and multiple breaks, was employed. In Bai-Perron method, to determine the variables of break point, $\mathrm{AR}(1)$ process with a constant reported to be giving significant results and better in catching break points Ben Aïssa et al. [78] was employed. The results obtained by carrying out AR(1) process on the level before administering the multiple-break test to the inflation series are given in Table 3.

At this stage, Bai-Perron test was run to explore how many significant or different subperiods there are in the series, that is, the existence of a structural break. While conducting the application, as there can be heterogeneity in the standard correction parameter error, as proposed in the work of Bai 

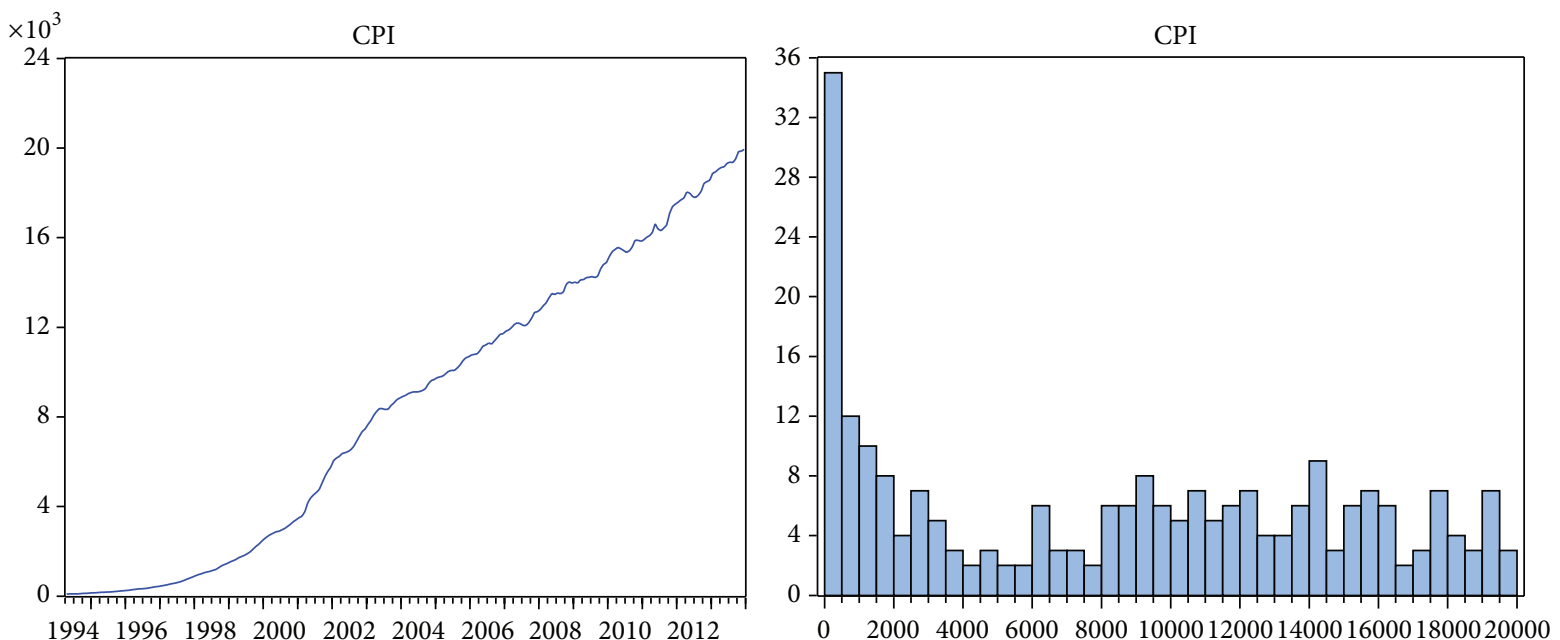

(a)
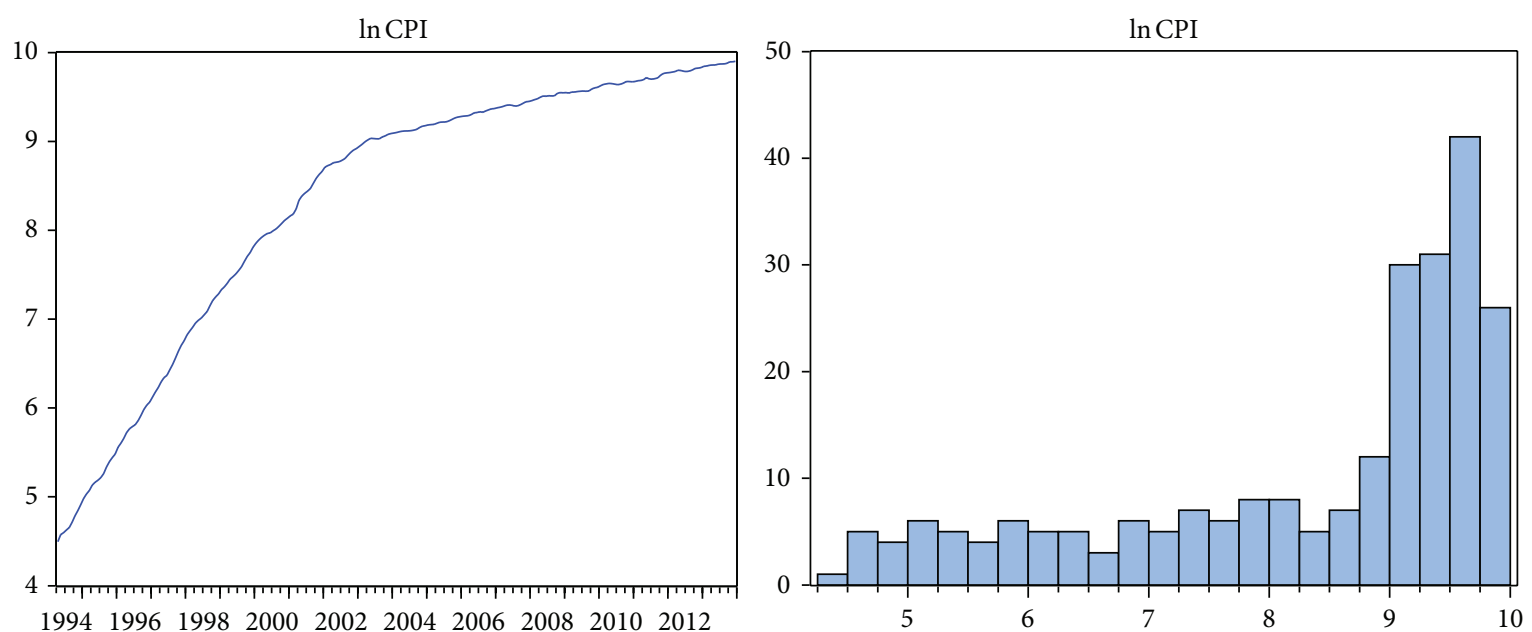

(b)
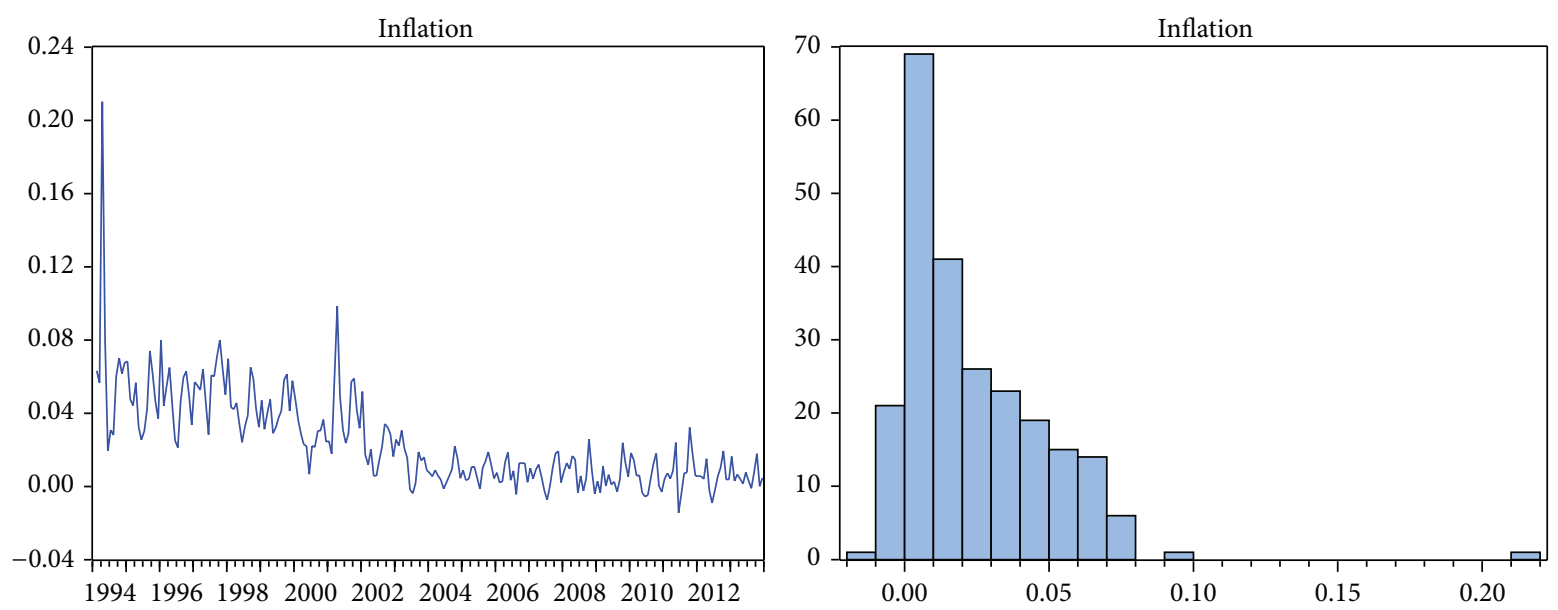

(c)

FIGURE 1: Graphical representations of CPI for its level (a), logarithm (b), and inflation series (c). 
TABLE 2: ADF unit root tests result for inflation.

\begin{tabular}{lccccc}
\hline Method & Model & Null hypothesis & Alternative hypothesis & Test statistics $(P$ value $)$ & Critical value \\
\hline \multirow{3}{*}{ ADF } & None & $\rho=1$ & $\rho<1$ & $-2.193745(0.0275)$ & -1.942236 \\
& Intercept & $\rho=1$ & $\rho<1$ & $-\mathbf{1 . 8 7 1 3 9 5}(0.3454)$ & -2.874143 \\
& Trend and intercept & $\rho=1$ & $\rho<1$ & $-7.911212(0.0000)$ & -3.429834 \\
\hline \multirow{3}{*}{ PP } & None & $\rho=1$ & $\rho<1$ & $-4.584029(0.0000)$ & -1.942164 \\
& Intercept & $\rho=1$ & $\rho<1$ & $-5.756209(0.0000)$ & -2.873492 \\
& Trend and intercept & $\rho=1$ & $\rho<1$ & $-9.830728(0.0000)$ & -3.428819 \\
\hline \multirow{2}{*}{ KPSS } & Intercept & Stationary & Nonstationary & $\mathbf{2 . 0 1 1 9 2 7}$ & 0.463000 \\
& Trend and intercept & Stationary & Nonstationary & $\mathbf{0 . 4 5 8 6 8 1}$ & 0.146000 \\
\hline
\end{tabular}

The one-sided critical value for ADF and PP were taken from [83].

The critical values for KPSS test were obtained from Table 1 in [45].

TABLE 3: Model results of AR(1) for inflation series.

\begin{tabular}{lcccc}
\hline Variable & Coefficient & Standard error & $t$-statistics & Significance \\
\hline$C$ & 0.006472 & 0.002108 & 3.069764 & 0.0024 \\
INF(-1) & 0.720925 & 0.082334 & 8.756080 & 0.0000 \\
\hline
\end{tabular}

TABLE 4: Bai-Perron structural break results using sequential test method for the inflation series.

\begin{tabular}{lccc}
\hline Break test & $F$-statistics & Scaled $F$-statistics & Critical value ${ }^{* *}$ \\
\hline 0 versus $1^{*}$ & 27.21147 & 54.42294 & 11.47 \\
1 versus 2 & 5.618205 & 11.23641 & 12.95 \\
\hline Number of breaks & \multicolumn{4}{c}{ Break dates } \\
\hline 1 & 2002:M02 \\
\hline${ }^{*}$ Significant at the 0.05 level. \\
${ }^{* *}$ Bai-Perron [67] critical values.
\end{tabular}

and Perron [67], $h=0.15$ was preferred. Moreover, as this procedure requires the least number of observations between breaks, that is, it requires minimum regime size, maximum 5 breaks were allowed in the study.

Since Bai and Perron [66] conducted a simulation study which expressed that sequential system produced better results, in our study sequential method is preferred and its results are presented in Table 4.

As a result of the applied test, only one structural break was detected in the inflation series in February 2002. The break date determined through econometric analysis will also be visually illustrated. Graphical display of this break and its parts is given in Figure 2.

When Figure 2 is analyzed, it is seen that the location of the break seems to support the statistical results obtained before. It is visible that there was a distinguishable change in the series in February 2002, which is the location of the break, and descriptive statistics belonging to the parts before and after the break are presented in Table 5 .

When the descriptive statistics belonging to the period prior to the break are analyzed, it is seen that while the monthly average inflation is $4.7 \%$ and standard deviation is $2.7 \%$, in the following of the break period, average is $0.83 \%$ and standard deviation is $0.89 \%$. Positive values found for both of the periods indicate that increments were mostly observed in the researched periods. Monthly average inflation value obtained before the break is 6 times greater than that obtained after the break and standard deviation before the break is 2.7 times greater than the standard deviation after the break and this shows that there is a significant level of difference between two periods. Histograms and visual descriptive statistics belonging to subperiods clearly show that the series was rightwards skewed before the break and after the break it became nearly symmetric. In a similar manner, while before the break, the center of the series appears to be quite high and pointed, in the other period, kurtosis gained the value that was very close to the kurtosis value of normal distribution that is " 3 ". Rightward skewness is the indication of big shocks in the related period; accordingly, it shows that the number of positive price increases is higher than that of negative price changes. Moreover, the lowest monthly inflation after February 2002 was in June 2011 which was realized as $-1.4 \%$ and the highest monthly inflation was in September 2002 which was realized as 3.4\%. In the period before the break, the lowest monthly inflation was $0.7 \%$ in June 2000 and the highest monthly inflation was $2.1 \%$ in April 1994. As can be seen, maximum and minimum monthly inflation values are around the crisis period and this supports the idea that in such periods greater changes are observed in inflation values.

\subsection{Conditional Mean Inflation Equation with Structural} Break in Mean and Variance. Univariate GARCH models consist of two equations. First one is mean equation describing the data observed as a function of other variables and error term. The second one of the variance equation shows the change of the variance as the function of past conditional variance and lagged error terms [40]. In this context, in the present study, volatility forecasting model best representing inflation uncertainty will be determined by constructing mean and variance equations to model inflation volatility.

In economies, there are some principal economic and financial variables regarded to be important determiners of inflation. Moreover, in order to be able to come up with the ideal forecasting, conditional mean and variance equations 

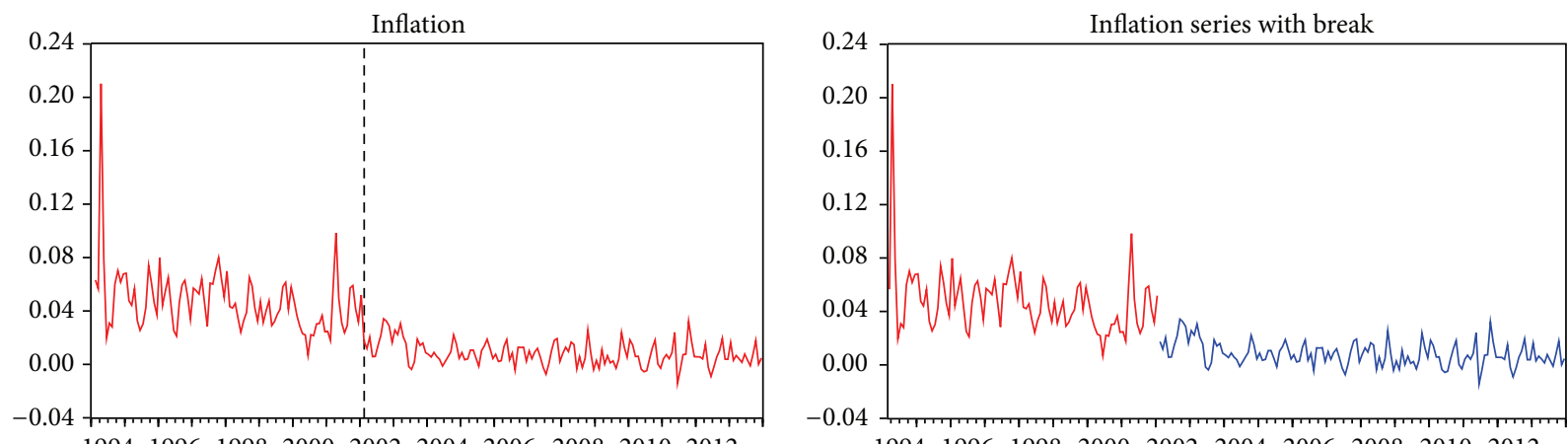

1994199619982000200220042006200820102012

- After break

Before break

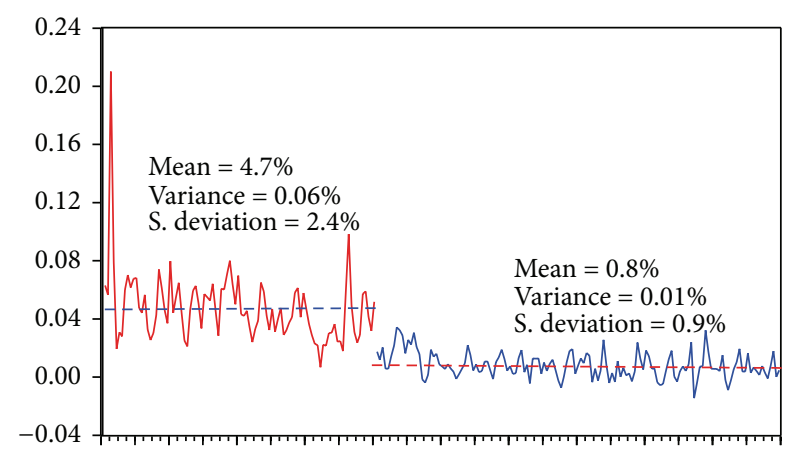

1994199619982000200220042006200820102012

(a)
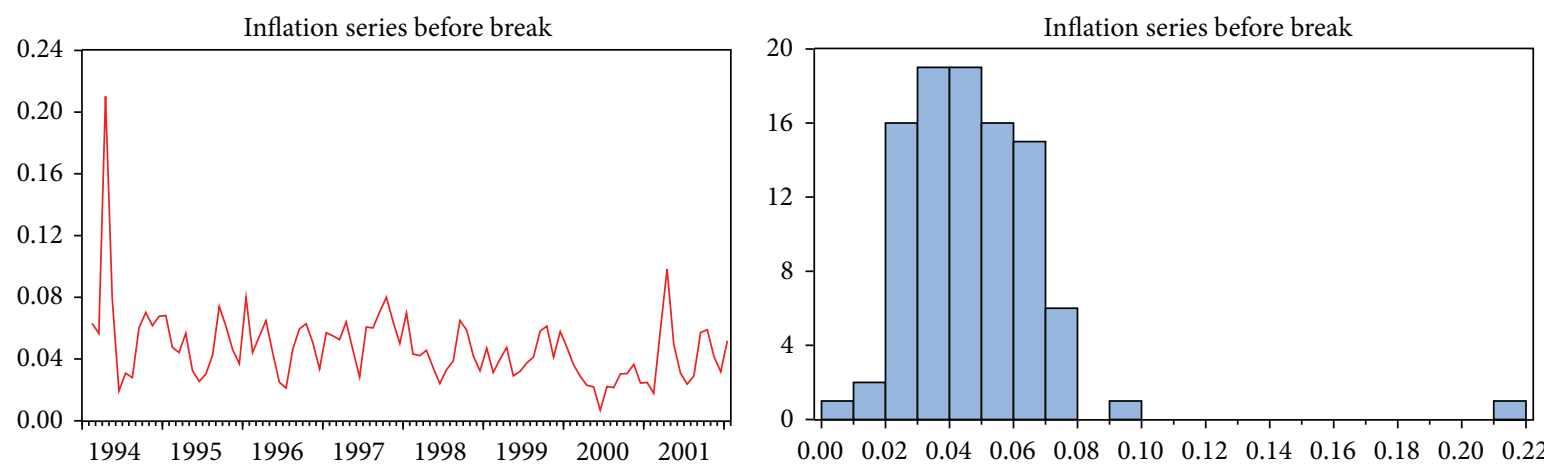

(b)
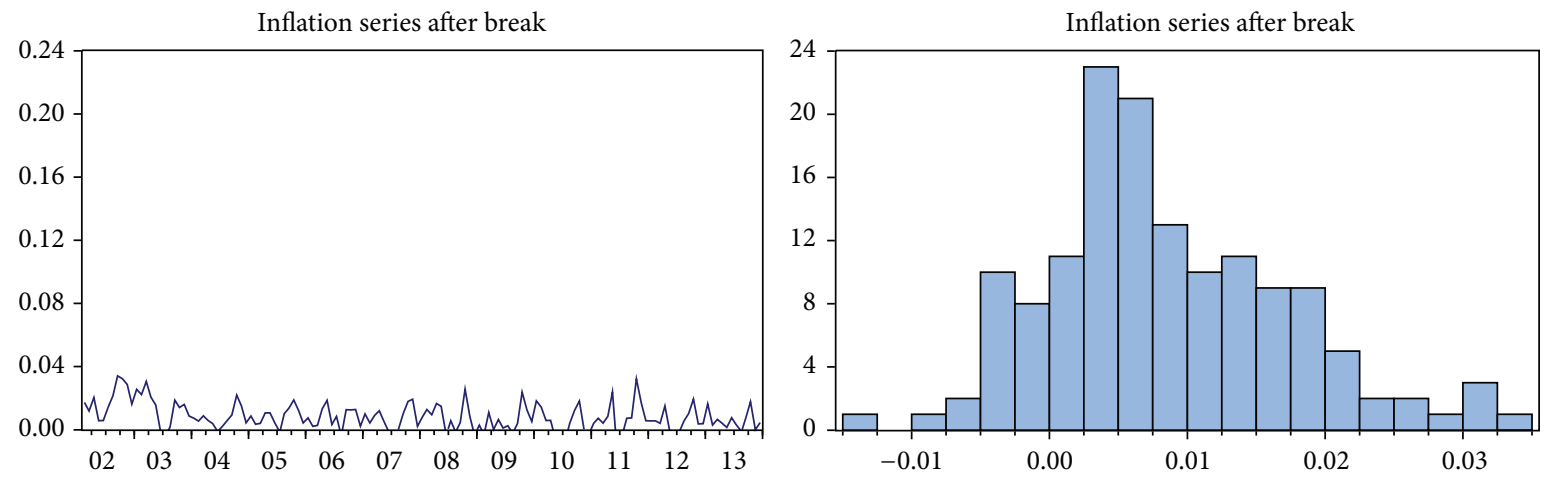

(c)

FIgURE 2: Time series graphs of inflation for two different subperiods. 
TABle 5: Descriptive statistics of inflation series for the break periods in mean.

\begin{tabular}{lccccccccc}
\hline Break & Mean & St. Dev. & Variance & Minimum & Median & Maximum & Skewness & Kurtosis & Obs. \\
\hline Before 2002:M01 & 0.04732 & 0.02402 & 0.00058 & 0.00676 & 0.04488 & 0.21013 & 3.29 & 23.2 & 96 \\
After 2002:M02 & 0.00833 & 0.00891 & 0.00008 & -0.014411 & 0.006602 & 0.034182 & 0.53 & 3.28 & 143 \\
\hline
\end{tabular}

TABLE 6: Coefficient and their statistics of the mean equation for inflation series.

\begin{tabular}{|c|c|c|c|c|}
\hline Variables & Coefficient & Standard error & $t$-statistics & Significance \\
\hline$D 1$ & 0.016930 & 0.003370 & 5.024028 & 0.0000 \\
\hline$D 1 * \operatorname{INF}(-1)$ & 0.460245 & 0.055982 & 8.221357 & 0.0000 \\
\hline$D 1 * \operatorname{INF}(-5)$ & 0.093542 & 0.039550 & 2.365172 & 0.0189 \\
\hline$D 2 * \operatorname{INF}(-1)$ & 0.444756 & 0.068491 & 6.493621 & 0.0000 \\
\hline$D 2 * \operatorname{INF}(-5)$ & 0.129793 & 0.060153 & 2.157715 & 0.0320 \\
\hline $\mathrm{SD}(1)$ & 0.011332 & 0.002104 & 5.387352 & 0.0000 \\
\hline $\mathrm{SD}(4)$ & 0.008563 & 0.002164 & 3.956521 & 0.0001 \\
\hline $\mathrm{SD}(6)$ & -0.009632 & 0.002160 & -4.459226 & 0.0000 \\
\hline $\mathrm{SD}(9)$ & 0.012423 & 0.002136 & 5.816294 & 0.0000 \\
\hline $\mathrm{SD}(10)$ & 0.013785 & 0.002120 & 6.501527 & 0.0000 \\
\hline Adjusted $R$-square & 0.836555 & \multicolumn{2}{|c|}{ AIC } & -6.565570 \\
\hline Log-likelihood & 778.1717 & \multicolumn{2}{|c|}{ SIC } & -6.417906 \\
\hline $\mathrm{FPE}^{*}$ & 0.824459 & \multicolumn{2}{|c|}{ HQ } & -6.506032 \\
\hline
\end{tabular}

${ }^{*}$ FPE information criteria have been calculated using the $(T+d) \mathrm{RSS} /(T-d)$ formula, where $T$ is the number of observation, $d$ is the number of parameters, and RSS is the residual sum squares [80].

should be correctly defined. Inflation series can be modeled as an $\operatorname{AR}(p)$ autoregressive equation as follows:

$$
\pi_{t}=\beta_{0}+\sum_{i=1}^{p} \beta_{i} \pi_{t-i}+\varepsilon_{t}
$$

where $p$ is the number of appropriate lags and $\varepsilon_{t}$ is identically independently normally distributed with zero mean and constant variance.

Though there are many economic and financial determiners of inflation used in macroeconomic applications, in the present study, autoregressive process that is the function of inflation's own lags is preferred and it is modeled by adding autoregressive $\mathrm{AR}$ term $\beta(L) \pi_{t}$ to the equation [20]. The reason for the selection of a model including an autoregressive term is, as in the case of many economic variables, its exhibiting of a strong persistence; in short, it is because of the fact that volatility in the series depends on former periods. As well known, in a single-variable regression, the sum of autoregressive coefficients is taken as a measurement of inflation persistence $[71,73]$.

As a result of the modeling works conducted for general inflation series in light of the above-mentioned data, the best mean equation was constructed using autoregressive process including the lags of inflation and seasonal dummy variables since the series is monthly. However, before forecasting any $\mathrm{ARCH}$ model for any time series, there are two steps to be taken. First one is to check whether the errors have unit root and the second one is to test ARCH effect. If the error term of the inflation regression model satisfies the assumption of no autocorrelation or stationarity, ARCH effect test will be valid. In case there is an ARCH effect, fitting GARCH-type models are adequate. Meanwhile, if there is not autocorrelation or heteroskedasticity in the error term then the standard mean equation can be used in forecasting.

However, if there is a strong autocorrelation in the error term obtained from the model, any test conducted to investigate ARCH effect can yield some confusion with its result [79]. As a result, at the end of any test researching any ARCH effect imposed on an error term with autocorrelation, it is possible to obtain erroneous result showing that there is an ARCH effect. Therefore, criteria values of final prediction error (FPE), one of the statistical criteria, having the capacity of adjusting the number of lags in such a way as to eliminate the error with autocorrelation for the purpose of checking the specification error in the inflation model and determining the suitable lag length, were preferred $[32,80]$.

In the most general form, $\operatorname{AR}(p)$ mean equation with a structural break can be written as follows:

$$
\pi_{t}=\mu+\sum_{i=1}^{n} \mu_{i} D_{i}+\sum_{i=1}^{n} \sum_{j=1}^{p} \emptyset_{i} D_{i} \pi_{t-j}+\sum_{j=1}^{m} \theta_{i} \mathrm{SD}_{j}+u_{t}
$$

where $n$ represents the number of breaks, $p$ represents appropriate lag number, and $m$ represents the number of seasonal dummy variables taking the value of " 1 " in the month related to SD and "0" in the other months. The best mean inflation display belonging to the general inflation series exposed to a structural break in 2000 is as follows and the statistics belonging to the most appropriate model with breaks are presented in Table 6 .

Among the models constructed with the inclusion of the break into the model for inflation series, statistical significance of all its coefficients and high adjusted $R^{2}$ value of 
TABLE 7: Stationarity diagnostics of the mean equation residuals with structural break for inflation series.

\begin{tabular}{lllccccc}
\hline & ADF & & \multicolumn{2}{c}{ PP } & \multicolumn{2}{c}{ KPSS } \\
\hline Intercept & $\begin{array}{l}\text { Trend and } \\
\text { intercept }\end{array}$ & None & Intercept & $\begin{array}{c}\text { Trend and } \\
\text { intercept }\end{array}$ & None & Intercept & $\begin{array}{c}\text { Trend and } \\
\text { intercept }\end{array}$ \\
-14.979 & -14.9971 & -15.008 & -14.979 & -14.9962 & -15.007 & 0.12157 & 0.063829 \\
$(0.0000)$ & $(0.0000)$ & $(0.0000)$ & $(0.0000)$ & $(0.0000)$ & $(0.0000)$ & $(0.46300)$ & $(0.14600)$ \\
\hline
\end{tabular}

* The one-sided critical value for ADF and PP were taken from [83].

** Kwiatkowski-Phillips-Schmidt-Shin (1992, Table 1 in [45]).

TABLE 8: Heteroskedasticity test results of the squared residuals of the mean equation with structural break for.

\begin{tabular}{lcc}
\hline Method & $F$-statistics & Obs. * R-square \\
\hline Breusch-Pagan-Godfrey & $2.647475(0.0045)$ & $24.83254(0.0057)$ \\
ARCH $(1)^{*}$ & $33.88254(0.0000)$ & $29.80427(0.0000)$ \\
\hline
\end{tabular}

* The number of lags was determined using AIC criterion.

TABLE 9: Bai-Perron structural break test of the variance break for inflation series.

\begin{tabular}{lccc}
\hline Break test & $F$-statistics & Scaled $F$-statistics & Critical value ${ }^{* *}$ \\
\hline 0 versus $1^{*}$ & 11.82528 & 11.82528 & 8.58 \\
1 versus 2 & 1.859458 & 1.859458 & 10.13 \\
\hline
\end{tabular}

Number of breaks Break dates

2001:M06

${ }^{*}$ Significant at the 0.05 level.

${ }^{* *}$ Bai-Perron [67] critical values.

the most appropriate model determined using FPE criterion prove its suitability. For all the models investigated within the study, no other $\operatorname{AR}(p)$ model presenting better results than the coefficients obtained from the mean equation with breaks was found.

In addition, when it is necessary to work with nonstationary series in models constructed without considering the break, the differencing procedure causes loss in longterm information. Moreover, the model with breaks allows working with the original series and with more limited number of parameters and less observation loss and this is an important advantage. It has already been stated that satisfaction of the stationarity hypothesis of the error term of the model and, if there is any, investigation of $\mathrm{ARCH}$ effect is necessary. In this regard stationarity of the errors of the equation is detected and it was found that the series is stationary. The results of the applied unit root tests are reported in Table 7.

This result also supports that the model is a good model. Since there is autocorrelation in the errors, the next step is to check whether there is any ARCH effect using heteroskedasticity tests and the obtained results are presented in Table 8.

As ARCH effect was detected in the error term of the mean equation, before carrying on with GARCH-type modeling, it is necessary to determine whether there is a break in error variance. When there are breaks in the mean, it is possible to see changes in the variance of the series and all of the events affecting the slope parameter will bring about changes in volatility. Following the approximate modeling of the square of the residuals obtained from the model into a constant value, Bai-Perron test has been reperformed and the results are presented in Table 9.

The results in Table 9 reveal that a structural break in variance occurred in June 2001 and brought about some changes in the volatility structure of the series for the periods specified. While variance series subperiod statistics belonging to the break location are given in Table 10, Figure 3 is also presented to provide some preliminary information.

When the descriptive statistics belonging to the period prior to the break are examined, it is seen that mean change in the series before the break is 3.3 times greater than the mean change after the break and the spread of change before the break is 4.3 times greater than the spread of change after the break. Therefore, it can be argued that the prebreak period has a greater volatility. The difference between the maximum and minimum decreased to a great extent after the break. When the histograms are analyzed, it is seen that though rightward skewness and kurtosis problems continue, their strength is reduced.

As a result, as it was found that there was a break in the mean of the variance of the errors in June 2001, forecasting models should be handled by considering the break in volatility forecasts for the inflation series.

4.4. Conditional Volatility Estimates of Inflation Series. Following the first phase of volatility forecasting models that is the determination of the mean equation, second phase that is the volatility forecasting will be proceeded by using the residuals of the mean equation model. In order to determine the volatility model that can best represent inflation uncertainty, we will use symmetric ARCH or GARCH forecasting. However, as explained before, the most serious disadvantage of these models is that they assume that the conditional variance gives symmetric responds to positive and negative shocks. Hence, in order to be able to eliminate this problem in the present study, one of the most frequently used asymmetric GJR-GARCH and EGARCH models was considered.

What is meant by the best appropriate GARCH representing ARCH effect in the error is the greatest log-likelihood and the model where the coefficients are statistically significant at the level of $5 \%$. Information criteria are not frequently used due to their failure in identifying the structure of GARCH-type processes [81]. Therefore, in the current study, in the determination of the model order for each ARCH, GARCH, EGARCH, and TGARCH, we use the maximum log-likelihood value and check whether they satisfy the 
TABLE 10: Descriptive statistics of the variance break periods for inflation series.

\begin{tabular}{lccccccccc}
\hline Break & Mean & St. dev. & Variance & Minimum & Median & Maximum & Skewness & Kurtosis & Obs. \\
\hline Before 2001:M05 & 1.38 & 2.54 & 0.0006452 & 0.000201 & 0.567 & 17.91 & 4.282011 & 25.0820 & 83 \\
After 2001:M06 & 0.413 & 0.588 & 0.0000346 & 0.0000651 & 0.217 & 4.19 & 3.101509 & 15.91156 & 151 \\
\hline
\end{tabular}

Note: The values except skewness and kurtosis are multiplied by 10000 as they are too small.

TABLE 11: Most appropriate obtained GARCH-type of models and their constraints for inflation series.

\begin{tabular}{|c|c|c|}
\hline Parameters & $\begin{array}{c}\text { Symmetric } \\
\mathrm{ARCH}\end{array}$ & $\begin{array}{c}\text { Asymmetric } \\
\text { EGARCH }\end{array}$ \\
\hline$\mu_{1}$ & $0.014242(0.0002)$ & $0.013473(0.0017)$ \\
\hline$\emptyset_{1}$ & $0.476255(0.0000)$ & $0.470196(0.0000)$ \\
\hline$\emptyset_{2}$ & $0.132779(0.0197)$ & $0.152300(0.0000)$ \\
\hline$\emptyset_{3}$ & $0.457314(0.0000)$ & $0.483289(0.0000)$ \\
\hline$\emptyset_{4}$ & $0.127269(0.0088)$ & $0.151228(0.0001)$ \\
\hline$\theta_{1}$ & $0.009516(0.0000)$ & $0.009930(0.0000)$ \\
\hline$\theta_{2}$ & $0.005730(0.0053)$ & $0.004573(0.0066)$ \\
\hline$\theta_{3}$ & $-0.007033(0.0002)$ & $-0.007627(0.0000)$ \\
\hline$\theta_{4}$ & $0.010459(0.0000)$ & $0.010297(0.0000)$ \\
\hline \multirow[t]{2}{*}{$\theta_{5}$} & $0.014071(0.0000)$ & $0.014152(0.0000)$ \\
\hline & \multicolumn{2}{|c|}{ Variance equation } \\
\hline$\omega$ & $3.28 E-05(0.0000)$ & $-14.69140(0.0000)$ \\
\hline$\alpha$ & $0.161211(0.0381)$ & $0.231022(0.0973)$ \\
\hline$\beta$ & & $-0.418258(0.0335)$ \\
\hline$\gamma$ & & $0.215865(0.0127)$ \\
\hline \multirow[t]{2}{*}{$V 1$} & $8.24 E-05(0.0004)$ & $1.855822(0.0000)$ \\
\hline & \multicolumn{2}{|c|}{ Constraints } \\
\hline Mean reverting level & \multicolumn{2}{|l|}{0.000039} \\
\hline Stationarity & 0.161211 & \\
\hline Nonnegativity & $3.28 E-05>0 \quad 0.161211>0$ & \\
\hline$\alpha_{i}-\gamma_{i}$ & & 0.015157 \\
\hline \multirow[t]{2}{*}{$\alpha_{i}+\gamma_{i}$} & & 0.446887 \\
\hline & \multicolumn{2}{|c|}{ Criteria } \\
\hline Adjusted $R^{2}$ & 0.831930 & 0.830115 \\
\hline Log-likelihood & 805.4523 & 809.2823 \\
\hline ARCH-LM ( $F$-statistics) & $0.903991(0.3427)$ & $0.212247(0.6454)$ \\
\hline Stationarity of residuals* & Stationary & Stationary \\
\hline Selected model & $\mathrm{ARCH}(1)$ & $\operatorname{EGARCH}(1,1)$ \\
\hline
\end{tabular}

Stationarity of selected the model residuals has been diagnosed using ADF, PP, and KPSS unit root tests with 5\% significance level.

Values between brackets represent the significant $P$ level.

TABLE 12: Sign bias asymmetry test results for inflation series.

\begin{tabular}{lc}
\hline Test & ARCH(1) \\
\hline Sign bias & $-1.77 E-05(0.4631)$ \\
Negative size bias & $-0.001307(0.6399)$ \\
Positive size bias & $0.008876(0.0000)$ \\
Joint test $\left(T * R^{2}\right)$ & $28.3151(3.12 E-06)$ \\
\hline${ }^{*}$ Values between brackets represent the significant $P$ level.
\end{tabular}

constraints belonging to the related models too. The GARCHtype model satisfying all of these conditions simultaneously is presented in Table 11.
One of the most essential problems in inflation research is the determination of the model that will best represent the inflation uncertainty series. Although it was stated that four different GARCH-type models would be used in the present study, none of GARCH and TGARCHs model were included in the study since these models did not satisfy neither parameters nor model constraints. Therefore, these results were not reported in Table 11. In conclusion, the models that can best represent $\mathrm{ARCH}$ effect on the error of inflation model were determined to be $\mathrm{ARCH}(1)$ and $\operatorname{EGARCH}(1,1)$. Yet, the models will be evaluated to see which one better represents and should be used. 
TABLE 13: Granger causality between inflation and its uncertainty in terms of break dates obtained from the mean and variance.

\begin{tabular}{|c|c|c|c|c|c|}
\hline$H_{0}$ hypothesis & $\begin{array}{c}\text { Before } \\
\text { 2001:M05 }\end{array}$ & $\begin{array}{c}\text { After } \\
\text { 2001:M06 }\end{array}$ & $\begin{array}{c}\text { Before } \\
\text { 2002:M01 }\end{array}$ & $\begin{array}{c}\text { After } \\
\text { 2002:M02 }\end{array}$ & Full sample \\
\hline Inflation does not Granger cause inflation uncertainty & $\begin{array}{c}26.7849 \\
(2 . E-13)\end{array}$ & $\begin{array}{c}21.5441 \\
(7 . E-26)\end{array}$ & $\begin{array}{c}51.7395 \\
(3 . E-15)\end{array}$ & $\begin{array}{c}10.0176 \\
(3 . E-14)\end{array}$ & $\begin{array}{c}17.6723 \\
(2 . E-27)\end{array}$ \\
\hline Inflation uncertainty does not Granger cause inflation & $\begin{array}{c}0.51315 \\
(0.7263) \\
\end{array}$ & $\begin{array}{c}5.87502 \\
(2 . E-08) \\
\end{array}$ & $\begin{array}{l}1.13238 \\
(0.3272) \\
\end{array}$ & $\begin{array}{c}5.02913 \\
(3 . E-07) \\
\end{array}$ & $\begin{array}{l}1.80032 \\
(0.0410) \\
\end{array}$ \\
\hline
\end{tabular}

Note: The appropriate number of lags has been determined using FPE criterion from VAR model.
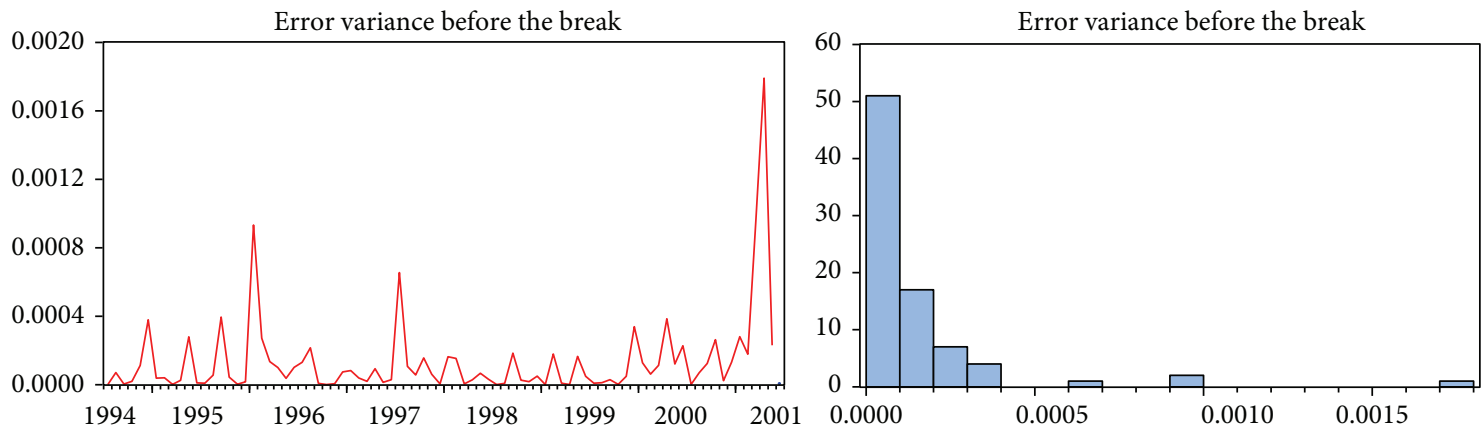

(a)
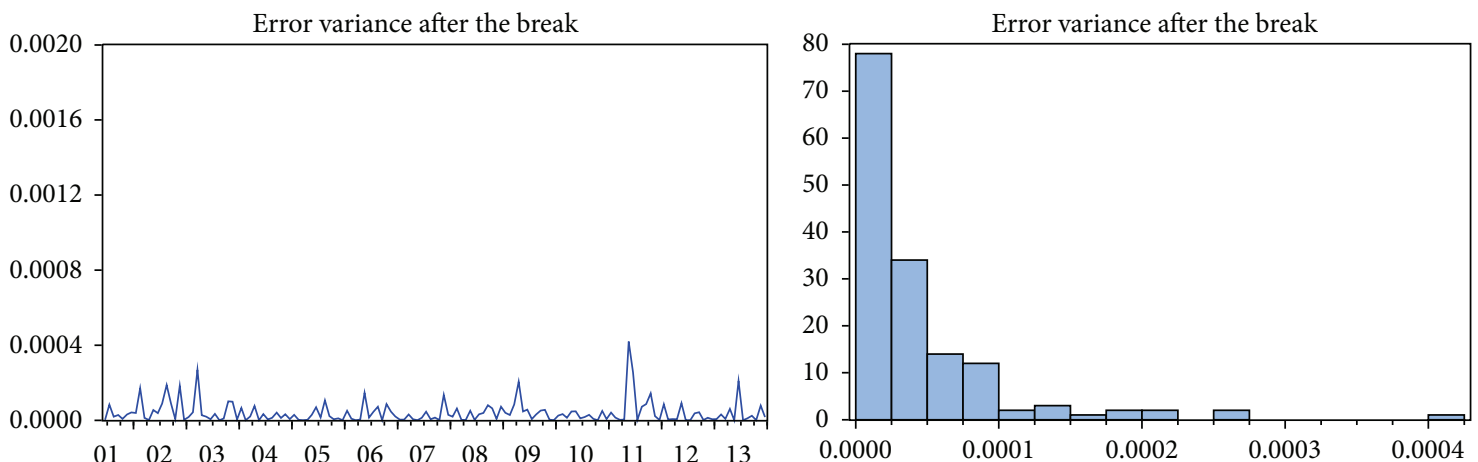

(b)

FIGURE 3: Time series graphs of the inflation series with variance break.

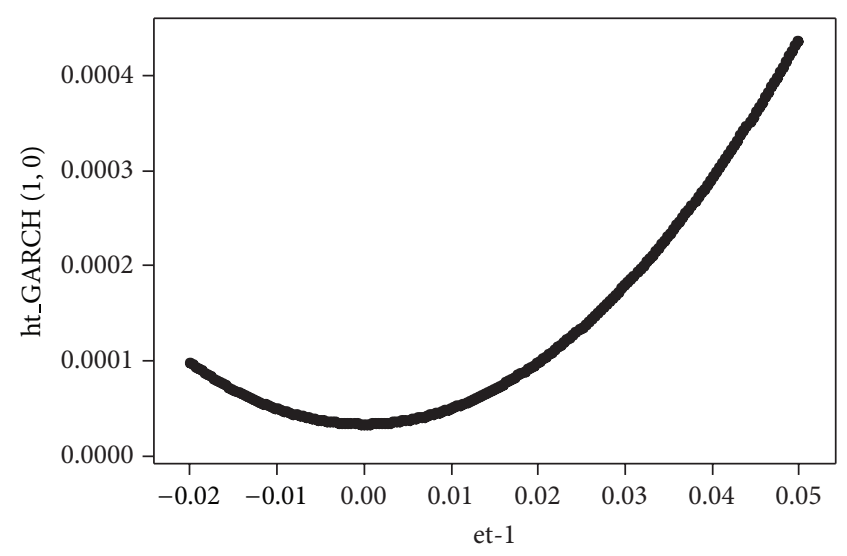

(a)

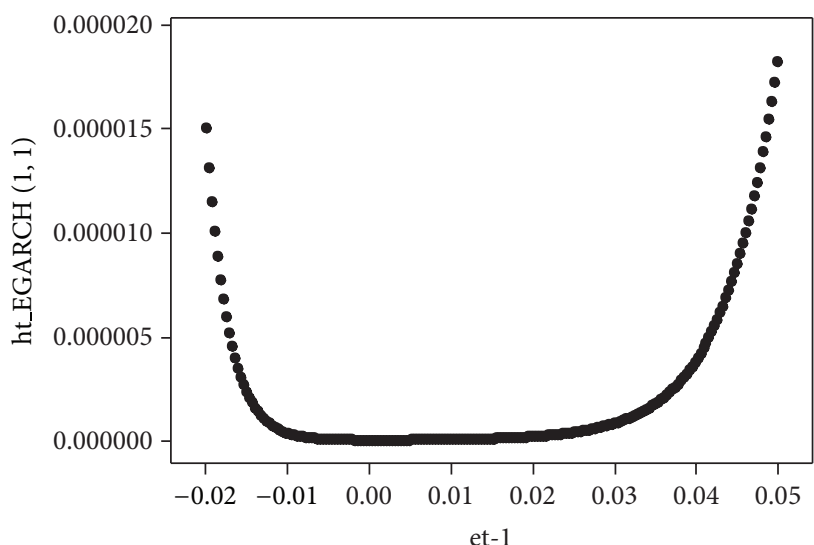

(b)

FIGURE 4: NIC graphs of the most appropriate GARCH-type models for inflation series. 


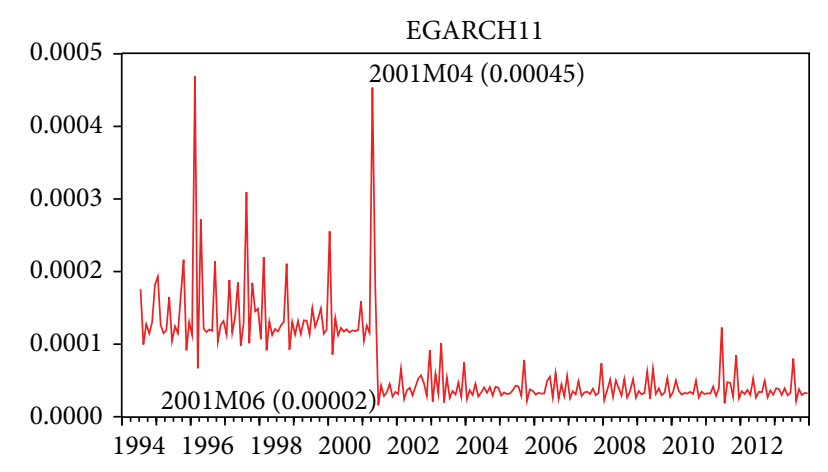

FIGURE 5: Inflation volatility graph of $\operatorname{EGARCH}(1,1)$ model.

The criteria that should be satisfied by symmetric GARCH-type models are different from those that should be satisfied by asymmetric GARCH-type models. In symmetric GARCH-type models, there are two criteria to be satisfied. The first is defined as mean reverting level. The mean reverting level defined as $\omega /(1-\alpha-\beta)$ should be positive. Another criterion besides coefficients' being positive is $\alpha_{i}<1$ stationarity criterion. When Table 10 is examined, it is seen that in ARCH model, $\alpha$ parameter meets the criteria of being positive, significant, and less than 1.

Though EGARCH model does not have any model criteria, except for parameter $\alpha$, model coefficients satisfy the significance at the level of $5 \%$ and asymmetry coefficient $\gamma$ is positive as expected. For financial time series, past negative shocks have the effect in the form of $\left(\alpha_{i}-\gamma_{i}\right)$ and positive shocks have the effect in the form of $\left(\alpha_{i}+\gamma_{i}\right)$ on EGARCH model conditional volatility. Since $\gamma_{i}$ is desired to be negative mostly in case of a negative shock $\left(\alpha_{i}-\gamma_{i}\right)$ is always greater than $\left(\alpha_{i}+\gamma_{i}\right)$. This situation mostly encountered in financial time series functions reversely for inflation and this time $\gamma_{i}$ is expected to be positive. Moreover, negative shock for inflation means good news and the effect of a shock that will create price change in descending direction on conditional volatility is expressed as $\left[\left(\alpha_{i}-\gamma_{i}\right)<\left(\alpha_{i}+\gamma_{i}\right)\right]$.

In addition, ARCH-LM test in both models shows that there is no ARCH effect left in residuals in the appropriate lag length. This confirms that the models filter the ARCH effect in the most appropriate manner and reflect in its own model. Finally, in order to check whether asymmetry coefficient is significant, sign bias and news impact curve will be drawn on.

In this regard, the results of sign bias test administered to test whether the best model is the symmetric or asymmetric GARCH-type model that will relieve the errors from heteroskedastic structure by using the mean equation of the inflation series and standardized errors obtained from ARCH(1) model are presented in Table 12.

When Table 12 was analyzed, it was found that the sign bias test coefficient expressing that both positive and negative shocks have different effects on future volatility and the negative size bias coefficient analyzing the different effects of small and big shocks on volatility are insignificant. In addition to this, as Engle and $\mathrm{Ng}$ [82] proved that integrated asymmetric test is more powerful than the other individual tests, only integrated test was used to test asymmetric effect in our study. The results of the integrated test, that is, all of the $\phi_{1}, \phi_{2}$ and $\phi_{3}$ parameters are different from zero, indicate the existence of asymmetry effect. At the same time, positive size bias coefficient indicating the effect of small and big positive shocks on volatility is significant. In this case, it can be argued that there is an asymmetric effect in the inflation series and thus, an increase with a positive direction occurring in the series particularly those including price changes results in different effects on volatility.

Second, it is possible to roughly determine asymmetry effect graphically through news impact curve (NIC). NIC that can be claimed to be the visual representative of the asymmetry level of positive and negative shocks shows the subsequent period volatility $\left(h_{t}\right)$ of past inflation shocks $\left(\varepsilon_{t-1}\right)$ stemming from various positive and negative news.

News impact curve representations for the most suitable GARCH-type models obtained for the inflation series were drawn and are presented in Figure 4.

Assuming that NIC is divided into two parts, left hand side represents a negative shock (bad news) and right hand side represents a positive shock (good news) and in general, negative side of the curve is more steep than the positive side. This case showing leverage effect in financial series can be reversely interpreted for inflation. As for inflation, negative shocks, that is, shocks resulting in a drop in inflation, represent good news and positive shocks represent bad news. In this connection, right hand side of the graph corresponds to positive shocks and in fact, it can be argued that this side is relatively steeper, is more sensitive to increases, and gives greater responds.

When all the above-given information is evaluated together, both of the models seem to be quite suitable for representing inflation uncertainty. In addition, $\operatorname{EGARCH}(1,1)$ model whose log-likelihood value is higher and $\gamma$ parameter whose asymmetry effect is checked by means of graphical displays and preliminary tests is significant is claimed to be the best representative of the model. It was revealed that inflation volatility series determined to be $\operatorname{EGARCH}(1,1)$ is stationary and ARCH effect was relieved from its residuals. This statistically shows that the conditional volatility model is an appropriate model for inflation uncertainty. In sum, all the analyses suggest that the conditional variance of inflation, that is, the obtained $\operatorname{EGARCH}(1,1)$ series, is the most suitable variable to represent inflation uncertainty. The graph of the series obtained from $\operatorname{EGARCH}(1,1)$ is shown in Figure 5.

When the graph is examined, the difference of the structure of inflation volatility between the period before June 2001 when the break in variance occurred and after this date can be clearly seen. High volatility values and changes of similar and different scales before the break and smaller values after the break suggest that the mean volatility between the two periods is quite different. As an example, during the period under investigation, the highest volatility occurred in April 2001. In the researched period, the second highest inflation value was observed to be 9.8\% in April 2001 and it dropped to $4.9 \%$ in May. 
The findings that are in compliance with the inflation series show that the volatility structure of inflation changes before the mean structure of the series. Whether this change occurring in volatility mean in June 2001 led to a change in the mean of inflation was investigated based on the mentioned break dates and the results are presented in Table 13.

When the results are interpreted, it can be argued that before the periods of both variance break and the break in the mean, inflation Granger causes inflation uncertainty but after the breaks the relationship becomes bidirectional. Thus, the structural level change occurring in uncertainty in a descending direction in 2001 led to structural level change in the mean of inflation and then bidirectional interaction started. The bidirectional relationship determined between inflation and inflation uncertainty for the period researched in the study concurs with the finding reported by [8] and was confirmed with Friedman-Ball hypothesis and CukiermanMeltzer hypothesis.

\section{Results, Findings, and Discussions}

In order to be able to reveal the inflation uncertainty structure of Turkey belonging to the period of 1994:01-2013:12, first, inflation series was obtained using CPI data. Before performing the modeling, based on the fact that the variables to be used in the study should be stationary, the unit root tests, ADF, PP, and KPSS, considered to be standard in the literature, were administered to the time series belonging to inflation. In addition to this, findings indicating that they are stationary according to some tests and they are not stationary according to some other tests led to confusion and raised some doubts about the possibility of structural breaks in the series.

As known well, most of the macroeconomic series are affected by the changes taking place in economies and structural break problem is encountered in many of them. Particularly, inflation dynamics are affected by internal and external shocks causing structural breaks. Moreover, it is necessary to investigate whether the changes estimated to be structural in economic variables are actually structural or not. Though the perception of the series provides some information about the number and location of the changes, it is not enough to derive results. Hence, such information should be supported with economic analyses and economically evaluated.

As Turkish economy has undergone important structural changes during its normal course, it is necessary to analyze the effects of structural breaks. Therefore, multiple-break test was administered using the Bai-Perron method to test the possibility of a structural change or break in the inflation series. The test revealed a structural break in the inflation series in February 2002. When the developments in the Turkish economy that may change the structure of the series in the period researched were analyzed, the year 2001 was found to be a turning point in terms of monetary policies.

The development making this year a turning point is the structural reforms implemented soon after the crisis. As a result of November 2000 and February 2001 crises, on 14th
April 2001, macrolevel economic precautions were put into effect to realize profound fiscal, economic, and legal changes called “Turkey's Transition to Strong Economy Program.” The main objectives of the program were to decrease the inflation, ensure fiscal discipline, and establish a suitable environment for economic growth.

Furthermore, in order to achieve these objectives, the program also emphasized the necessity for the country to adopt inflation targeting, liberate the exchange rates, ensure the freedom of the Central Bank, change the organizational and legal structures to create a suitable environment for economic activities, develop free market economy, and decrease the load on the shoulders of public sector. In this context, in the related period, fluctuation of exchange rates was allowed and 15 regulations, including the one making Turkish Republic Central Bank autonomous, were enacted and in this way, implicit inflation targeting was adopted. After the declaration of all these changes and targets, positive results particularly in inflation were observed. Given that since 2002 no other structural change has occurred in inflation and inflation displayed a steady pattern, it can be argued that the program achieved its objective in terms of decreasing inflation.

After identifying the structural break in the course of inflation, modeling was performed by taking this break into consideration and it was determined that the residuals of the best mean inflation equation with a break are stationary and are having the effect of $\mathrm{ARCH}$ due to heterogeneity in variance. To eliminate such a problem, before applying the GARCH-type modeling, diagnosis of whether there was any break in the variance of the residuals was performed. Then it was determined that a structural break occurred in the variance in June 2001. Based on the fact that inflation volatility structure changes earlier than the mean structure, it can be argued that the program implemented in 2001 decreased the inflation-related changes and accordingly, the volatility. This process on which the uncertainty-related developments had some effects can be claimed to lead to a change in the mean of inflation.

For the forecasting of inflation volatility, by considering the break occurring in the mean in February 2002 and the break occurring in the variance in June 2001, research on GARCH-type model was constructed. Among the most widely used GARCH-type symmetric models, ARCH and GARCH and among the asymmetric models, GJR-GARCH (TGARCH) and EGARCH were examined to find the most appropriate one. In addition, GARCH and TGARCH models not satisfying model and parameter criteria were discarded and $\operatorname{ARCH}(1)$ and $\operatorname{EGARCH}(1,1)$ were determined to be the most appropriate models. When these most suitable models were compared, $\operatorname{EGARCH}(1,1)$ model was found to be a better inflation uncertainty representative. Moreover, significance of the asymmetry coefficient in the model was confirmed statistically by asymmetry tests and visually by NIC. From these methods, it was understood that inflation volatility is positive; that is, it gives a different respond to price increases from the respond it gives to price drops, namely, asymmetric respond. Therefore, in the determination of inflation uncertainty, $\operatorname{EGARCH}(1,1)$ model was preferred. 
Moreover, it was investigated whether changing of the volatility structure of inflation before the mean structure of inflation led to any change in the structure of the causal relation between them. The results showed that the breaks did not only change the inflation structure but also affected the direction of the causality relationship between inflation and uncertainty. More clearly, while before 2002, FriedmanBall hypothesis suggesting that inflation is the cause of uncertainty was valid, and after the break, bidirectional causality showing that inflation and uncertainty are in a mutual interaction was determined. Moreover, when all the series is taken as a whole without considering the break, bidirectional causality in the series is observed.

When the period of 1994:01-2013:12 in Turkey was evaluated through the obtained results, it was found that a break occurred in inflation volatility in June 2001 and a break occurred in mean inflation structure in February 2002. After these breaks, significant differences were observed in the inflation mean and uncertainty structures. Moreover, this change was also seen in the causality relationship between them. Therefore, we suggest for similar future studies that the period after 2002 may be taken into account as long as no unusual change has been observed in the course of Turkish economy.

\section{Conflict of Interests}

The authors declare that there is no conflict of interests regarding the publication of this paper.

\section{References}

[1] B. S. Omotosho and S. I. Doguwa, "Understanding the dynamics of inflation volatility in Nigeria: a GARCH perspective," $C B N$ Journal of Applied Statistics, vol. 3, no. 2, pp. 51-74, 2013.

[2] S. Banerjee, Essays on inflation volatility [Doctoral thesis], Department of Economics, Finance and Business, Durham Business School, University of Durham, 2013.

[3] K. B. Grier and M. J. Perry, "On inflation and inflation uncertainty in the G7 countries," Journal of International Money and Finance, vol. 17, no. 4, pp. 671-689, 1998.

[4] A. Tsyplakov, "The links between inflation and inflation uncertainty at the longer horizon," Economics Education And Research Consortium: Russia and CIS, Working Paper 10/09E, 2010.

[5] A. M. Okun, "The mirage of steady inflation," in Brookings Papers on Economic Activity, vol. 2, pp. 485-498, 1971.

[6] M. Friedman, "Nobel lecture: inflation and unemployment," Journal of Political Economy, vol. 85, no. 3, pp. 451-472, 1977.

[7] L. Ball, "Why does high inflation raise inflation uncertainty?" Journal of Monetary Economics, vol. 29, no. 3, pp. 371-388, 1992.

[8] H. F. Erdem and R. Yamak, "Türkiye'de enflasyon ve enflasyon belirsizliği: kalman filtre yaklaşımı," Çukurova Üniversitesi İ̈BF Dergisi, vol. 17, no. 2, pp. 65-80, 2013.

[9] K. M. Emery, "Inflation and its variability: an alternative specification," Applied Economics, vol. 25, no. 1, pp. 43-46, 1993.

[10] P. Demetriades, M. Karaoglu, and S. H. Law, "One date, one break?" in Proceedings of the 38th Annual Conference Of The Money, Macro and Finance Research Group, University of York, York, UK, September, 2006.
[11] R. F. Engle, "Autoregressive conditional heteroscedasticity with estimates of the variance of United Kingdom inflation," Econometrica, vol. 50, no. 4, pp. 987-1007, 1982.

[12] W. Miles and S. Schreyer, "Inflation costs, uncertainty costs and emerging markets," Journal of Economic Development, vol. 34, no. 2, pp. 169-183, 2009.

[13] A. A. Drakos, G. P. Kouretas, and L. P. Zarangas, "Forecasting financial volatility of the Athens stock exchange daily returns: an application of the asymmetric normal mixture GARCH model," International Journal of Finance and Economics, vol. 15, no. 4, pp. 331-350, 2010.

[14] D. Zapodeanu, M. I. Cociuba, and S. Petris, "The inflationinflation uncertainty nexus in Romania," in Proceedings of the International Conference "Monetary, Banking and Financial Issues in Central and Eastern EU Member Countries: How Can Central and Eastern EU Members Overcome the Current Economic Crisis?”, Iaşi, Romania, April 2014.

[15] B. Russell, "ARCH and structural breaks in United States inflation," Dundee Discussion Papers in Economics, Working Paper 277, October 2013.

[16] R. T. Baillie, C.-F. Chung, and M. A. Tieslau, "Analysing inflation by the fractionally integrated Arfima-Garch model," Journal of Applied Econometrics, vol. 11, no. 1, pp. 23-40, 1996.

[17] T. Caporale and B. McKiernan, "High and variable inflation: further evidence on the friedman hypothesis," Economics Letters, vol. 54, no. 1, pp. 65-68, 1997.

[18] S. Fountas, "The relationship between inflation and inflation uncertainty in the UK: 1885-1998," Economics Letters, vol. 74, no. 1, pp. 77-83, 2001.

[19] Y. Hwang, "Relationship between inflation rate and inflation uncertainty," Economics Letters, vol. 73, pp. 179-186, 2001.

[20] A. Kontonikas, "Inflation and inflation uncertainty in the United Kingdom, evidence from GARCH modelling," Economic Modelling, vol. 21, no. 3, pp. 525-543, 2004.

[21] J. Thornton, "High and variable inflation: further evidence on the Friedman hypothesis," South African Journal of Economics, vol. 74, no. 2, pp. 167-171, 2006.

[22] B. K. Wilson, "The links between inflation, inflation uncertainty and output growth: new time series evidence from Japan," Journal of Macroeconomics, vol. 28, no. 3, pp. 609-620, 2006.

[23] J. E. Payne, "Inflation and inflation uncertainty: evidence from the Caribbean region," Journal of Economic Studies, vol. 35, no. 6, pp. 501-511, 2008.

[24] J. Thornton, "The relationship between inflation and inflation uncertainty in emerging market economies," Southern Economic Journal, vol. 73, no. 4, pp. 858-870, 2007.

[25] J. Thornton, "Money, output and inflation in African economies," South African Journal of Economics, vol. 76, no. 3, pp. 356-366, 2008.

[26] N. Apergis, "Inflation, output growth, volatility and causality: evidence from panel data and the G7 countries," Economics Letters, vol. 83, no. 2, pp. 185-191, 2004.

[27] S. Fountas, M. Karanasos, and J. Kim, "Inflation uncertainty, output growth uncertainty and macroeconomic performance," Oxford Bulletin of Economics and Statistics, vol. 68, no. 3, pp. 319-343, 2006.

[28] C. Conrad and M. Karanasos, "Dual long memory in inflation dynamics across countries of the Euro Area and the link between inflation uncertainty and macroeconomic performance," Studies in Nonlinear Dynamics \& Econometrics, vol. 9, no. 4, article 5, 2005. 
[29] S. A. Javed, S. A. Khan, A. Haider, and F. Shaheen, "Inflation and inflation uncertainty nexus: empirical evidence from Pakistan," International Journal of Economics and Financial Issues, vol. 2, no. 3, pp. 348-356, 2012.

[30] M. H. Berument, Y. Yalcin, and J. Yildirim, "Inflation and inflation uncertainty: a dynamic framework," Physica A: Statistical Mechanics and Its Applications, vol. 391, no. 20, pp. 4816-4826, 2012.

[31] A. J. Samimi, M. Abdollahi, and S. Ghader, "Inflation and inflation uncertainty: evidence from MENA," Universal Journal of Management and Social Sciences, vol. 2, no. 1, pp. 57-62, 2012.

[32] B. Neyapti and N. Kaya, "Inflation and inflation uncertainty in Turkey: evidence from the past two decades," Yapi Kredi Economic Review, vol. 12, no. 2, pp. 21-25, 2001.

[33] F. Telatar and E. Telatar, "The relationship between inflation and different sources of inflation uncertainty in Turkey," Applied Economics Letters, vol. 10, no. 7, pp. 431-435, 2003.

[34] H. Akyazı and S. Artan, "Türkiye'de Enflasyon-Enflasyon Belirsizliği İlişkisi ve Enflasyon Hedeflemesinin Enflasyon Belirsizliğini Azaltmadaki Rolü,” Bankacılar Dergisi 48, 2004.

[35] S. Oltulular and H. Terzi, "Yüksek enflasyon enflasyon belirsizliğini artırıyor mu?” İstanbul Üniversitesi İktisat Fakültesi Ekonometri ve Istatistik Dergisi, vol. 3, 2006.

[36] E. Severve and M. Demir, "Enflasyon hedeflemesi sürecinde enflasyon ve enflasyon belirsizliği ilişkisinin analizi," Marmara Üniversitesi I.I.I.B.F. Dergisi, vol. 24, no. 1, pp. 41-63, 2008.

[37] C. Saatçioğlu and L. Korap, "New time series evidence for the causality relationship between inflation and inflation uncertainty in the Turkish economy," Doğuş Üniversitesi Dergisi, vol. 10, no. 2, pp. 235-248, 2009.

[38] M. H. Berument, Y. Yalcin, and J. O. Yildirim, "The inflation and inflation uncertainty relationship for Turkey: a dynamic framework," Empirical Economics, vol. 41, no. 2, pp. 293-309, 2011.

[39] B. Doğru, "Farklı para politikası rejimlerinde enflasyon belirsizliği ve enflasyon ilişkisi," BDDK Bankacilik ve Finansal Piyasalar, vol. 7, no. 2, pp. 77-99, 2013.

[40] L. Hentschel, "All in the family Nesting symmetric and asymmetric GARCH models," Journal of Financial Economics, vol. 39, no. 1, pp. 71-104, 1995.

[41] C. R. Nelson and C. R. Plosser, "Trends and random walks in macroeconmic time series: some evidence and implications," Journal of Monetary Economics, vol. 10, no. 2, pp. 139-162, 1982.

[42] J. Glynn, N. Perera, and R. Verma, "Unit root tests and structural breaks: a survey with applications," Revista de Metodos Cuantitativos para la Economia y la Empresa, vol. 3, pp. 63-79, 2007.

[43] D. A. Dickey and W. A. Fuller, "Likelihood ratio statistics for autoregressive time series with a unit root," Econometrica, vol. 49, no. 4, pp. 1057-1072, 1981.

[44] P. C. B. Phillips and P. Perron, "Testing for unit root in time series regression," Biometrika, vol. 75, pp. 335-346, 1988.

[45] D. Kwiatkowski, P. C. B. Phillips, P. Schmidt, and Y. Shin, “Testing the null hypothesis of stationarity against the alternative of a unit root," Journal of Econometrics, vol. 54, no. 1-3, pp. 159-178, 1992.

[46] M. Feridun, B. Sawhney, and A. Jalil, "Stock market and investment in Turkey: evidence from cointegration and causality tests," Ekonomska Istrazivanja, vol. 22, no. 4, pp. 17-29, 2009.

[47] M. B. Shrestha and K. Chowdhury, "A sequential procedure for testing unit roots in the presence of structural break in time series data," Tech. Rep. Working Paper Series, University of Wollongong Economics, 2005.
[48] D. Ben-David, R. L. Lumsdaine, and D. H. Papell, "Unit roots, postwar slowdowns and long-run growth: evidence from two structural breaks," Empirical Economics, vol. 28, no. 2, pp. 303319, 2003.

[49] P. Perron, "The great crash, the oil price shock, and the unit root hypothesis," Econometrica, vol. 57, no. 6, pp. 1361-1401, 1989.

[50] E. Zivot and D. W. K. Andrews, "Further evidence on the great crash, the oil-price shock, and the unit-root hypothesis," Journal of Business \& Economic Statistics, vol. 20, no. 1, pp. 25-44, 2002.

[51] P. Perron, "Further evidence on breaking trend functions in macroeconomic variables," Journal of Econometrics, vol. 80, no. 2, pp. 355-385, 1997.

[52] S.-H. Poon and C. W. J. Granger, "Forecasting volatility in financial markets: a review," Journal of Economic Literature, vol. 41, no. 2, pp. 478-539, 2003.

[53] T. Bollerslev, "Generalized autoregressive conditional heteroskedasticity," Journal of Econometrics, vol. 31, no. 3, pp. 307327, 1986

[54] W. K. Li, S. Ling, and M. McAleer, "Recent theoretical results for time series models with GARCH errors," Journal of Economic Surveys, vol. 16, no. 3, pp. 245-270, 2002.

[55] C. Brooks, Introductory Econometrics for Finance, Cambridge University Press, 2nd edition, 2008.

[56] R. F. Engle, "Risk and volatility: econometric models and financial practice," Nobel Lecture, 2003.

[57] M. Karmakar, "Asymmetric volatility and risk-return relationship in the Indian stock market," South Asia Economic Journal, vol. 8, no. 1, pp. 99-116, 2007.

[58] T. G. Andersen and T. Bollerslev, "Answering the skeptics: yes, standard volatility models do provide accurate forecasts," International Economic Review, vol. 39, no. 4, pp. 885-905, 1998.

[59] D. B. Nelson, "Conditional heteroskedasticity in asset returns: a new approach," Econometrica, vol. 59, no. 2, pp. 347-370, 1991.

[60] E. Zivot and J. Wang, Modelling Financial Time Series with SPlus, University of Washington, Washington, DC, USA, 2nd edition, 2006.

[61] C. Alexander, Market Risk Analysis Volume II Practical Financial Econometrics, John Wiley \& Sons, Chichester, UK, 2008.

[62] L. R. Glosten, R. Jagannathan, and D. E. Runkle, "On the relation between the expected value and the volatility of the nominal excess return on stocks," The Journal of Finance, vol. 48, no. 5, pp. 1779-1801, 1993.

[63] J.-M. Zakoian, “Threshold heteroskedastic models," Journal of Economic Dynamics and Control, vol. 18, no. 5, pp. 931-955, 1994.

[64] J. Bai, "Estimating multiple breaks one at a time," Econometric Theory, vol. 13, no. 3, pp. 315-352, 1997.

[65] J. Bai and P. Perron, "Estimating and testing linear models with multiple structural changes," Econometrica, vol. 66, no. 1, pp. 4778, 1998.

[66] J. Bai and P. Perron, "Computation and analysis of multiple structural change models," Journal of Applied Econometrics, vol. 18, no. 1, pp. 1-22, 2003.

[67] J. Bai and P. Perron, "Critical values for multiple structural change tests," The Econometrics Journal, vol. 6, no. 1, pp. 72-78, 2003.

[68] J. Bai and P. Perron, "Multiple structural change models: a simulation analysis," in Forthcoming in Econometric Essays, D. Corbea, S. Durlauf, and B. E. Hansen, Eds., Cambridge University Press, Cambridge, Mass, USA, 2005.

[69] W. Enders and T. Sandler, "After 9/11 IS IT all different now?" Journal of Conflict Resolution, vol. 49, no. 2, pp. 259-277, 2005. 
[70] S. Antoshin, A. Berg, and M. Souto, "Testing for structural breaks in small samples," IMF Working Paper African Department WP/08/75, 2008.

[71] C. Zhang and J. Clovis, "Modeling US inflation dynamics: persistence and monetary policy regimes," Empirical Economics, vol. 36, no. 2, pp. 455-477, 2009.

[72] M. V. Endrész, "Structural breaks and financial risk management," Working Paper 11, Magyar Nemzeti Bank, 2004.

[73] I. Pelipas, "Multiple structural breaks and inflation persistence in Belarus," Working Paper Series BEROC WP 21, Belarusian Economic Research and Outreach Center, December 2012.

[74] V. W. Roth, Final Report of the Advisory Commission to Study the Consumer Price Index, 10th Congress, 2nd Session, U.S. Government Printing Office, Washington, DC, USA, 1996.

[75] D. Norman and A. Richards, "The forecasting performance of single equation models of inflation," Economic Record, vol. 88, no. 280, pp. 64-78, 2012.

[76] N. G. Mankiw, Macroeconomics, Worth Publishers, 5th edition, 2002.

[77] K. Fregert, Practical Macroeconomics A Manual with Spreadsheet Exercises, Department of Economics Lund University, 2000.

[78] M. S. Ben Aïssa, M. Boutahar, and J. Jouini, "Bai and Perron's and spectral density methods for structural change detection in the US inflation process," Applied Economics Letters, vol. 11, no. 2, pp. 109-115, 2004.

[79] T. F. Cosimano and D. W. Jansen, "Estimates of the variance of U.S. inflation based upon the ARCH model: comment," Journal of Money, Credit and Banking, vol. 20, no. 3, part 1, pp. 409-421, 1988.

[80] V. K. S. Liew, "Which lag length selection criteria should we employ," Economics Bulletin, vol. 3, no. 33, pp. 1-9, 2004.

[81] M. Karoglou, P. Demetriades, and S. H. Law, "One date, one break?” Empirical Economics, vol. 41, no. 1, pp. 7-24, 2011.

[82] R. F. Engle and V. K. Ng, "Measuring and testing the impact of news on volatility," The Journal Of Finance, vol. 48, no. 5, pp. 1749-1778, 1993.

[83] J. G. Mackinnon, "Numerical distribution functions for unit root and cointegration tests," Journal of Applied Econometrics, vol. 11, no. 6, pp. 601-618, 1996. 


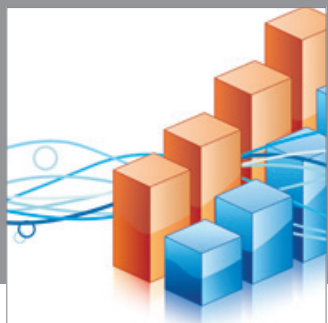

Advances in

Operations Research

mansans

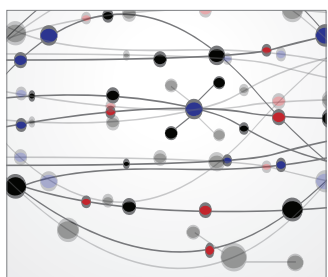

The Scientific World Journal
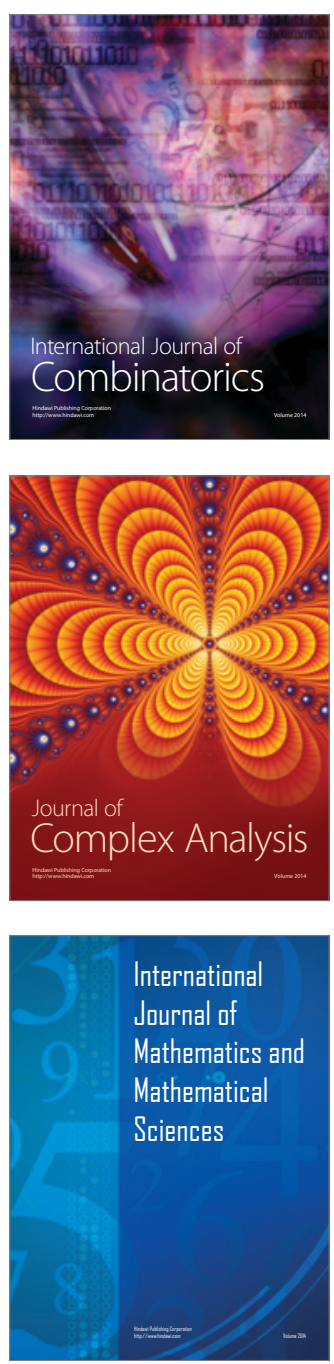
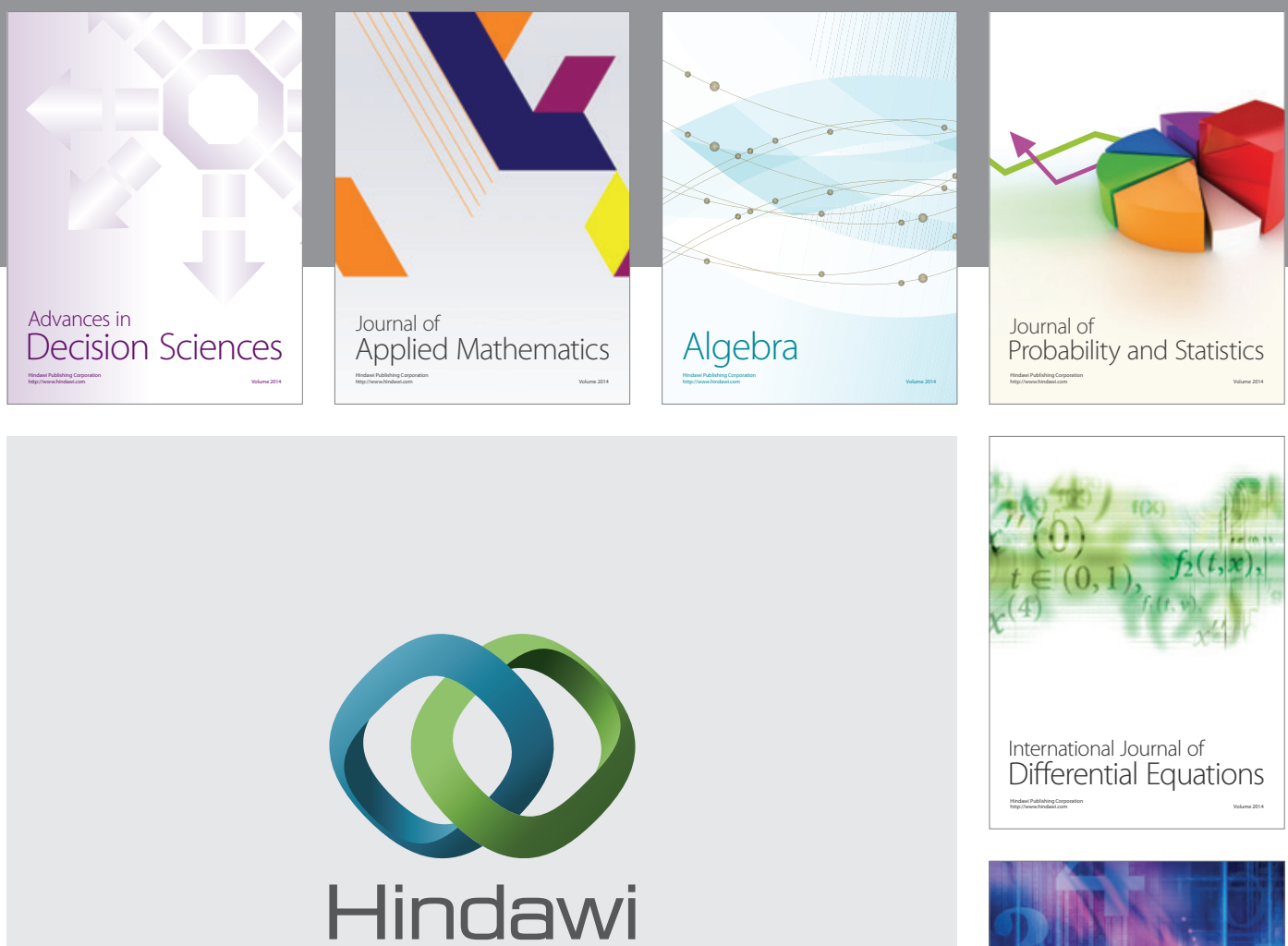

Submit your manuscripts at http://www.hindawi.com
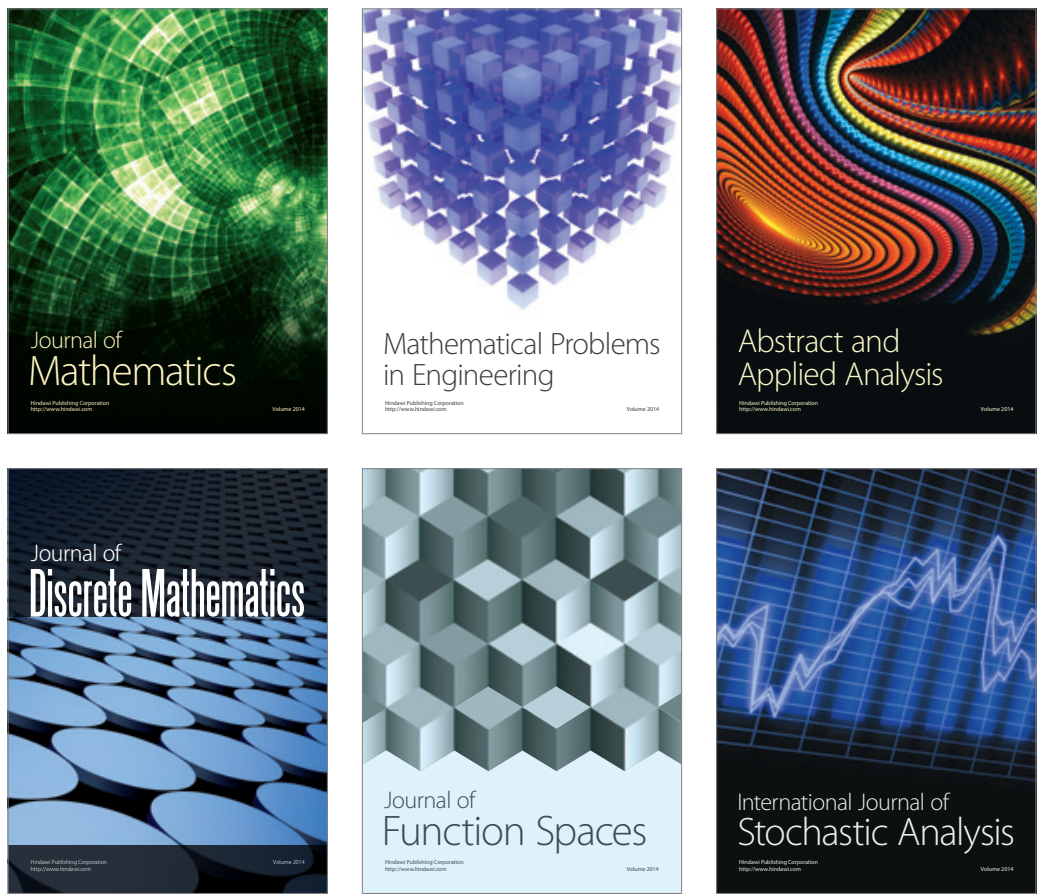

Journal of

Function Spaces

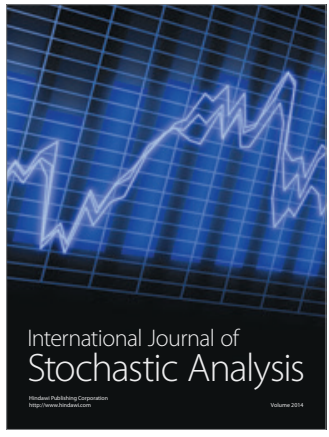

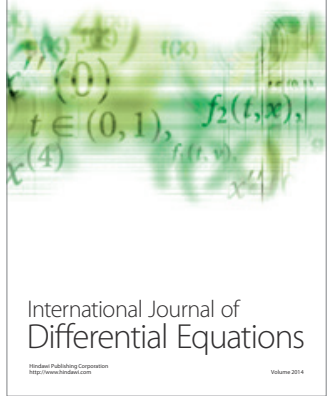
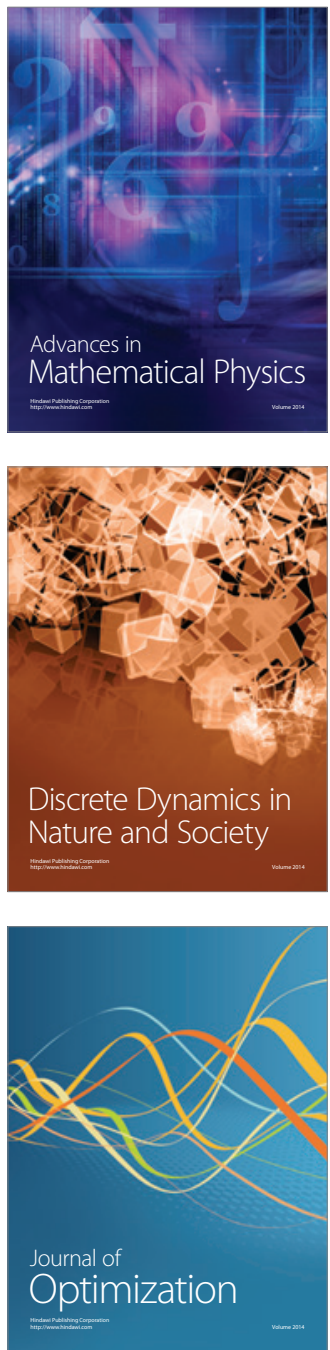